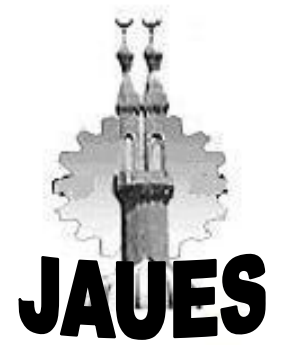

Journal of Al Azhar University Engineering Sector

Vol. 12, No. 42, January, 2017,310 -327

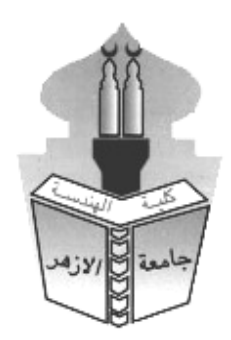

$$
\begin{aligned}
& \text { دور تطبيقاث ثقتية النانو في تحقيق العمارة المستدامه } \\
& \text { محمد سيف النصر احمد } \\
& \text { قسم الهندسة المعمارية ـ كلية الهندسة بالمطرية ـ جامعة حلوان }
\end{aligned}
$$

\begin{abstract}
:
The Architect care about the materials and raw materials properties to achieve the design requirements, and the latest science that brought about a boom in this area is Nanotechnology which can improve the material properties, add a new property, or production of new material, which leads to a marked difference in the ways of thinking and architectural design, and the world move to achieve the principles of sustainability in architecture because it is one of the most sectors negatively on the environment but the results so far away from the hoped.

The Research supposed possibility of using nanotechnology to improve the performance of buildings to achieve the principles of sustainability, and to reach to achieve this hypothesis The research is divided into two main parts: - Theoretical Study: Recognition at Nanotechnology and its applications in various fields and its impact on architecture in terms of materials and devices used, and the study of sustainable architecture system and its evaluation systems and how to take advantage of this field by Nano materials and devices . Analytical Study: Studying of nanotechnology applications to achieve sustainability standards in architecture through examples of the global trend of sustainable projects, analysis and use of nanotechnology applications and what are the expected success rates, and then conclude to the results and recommendations
\end{abstract}

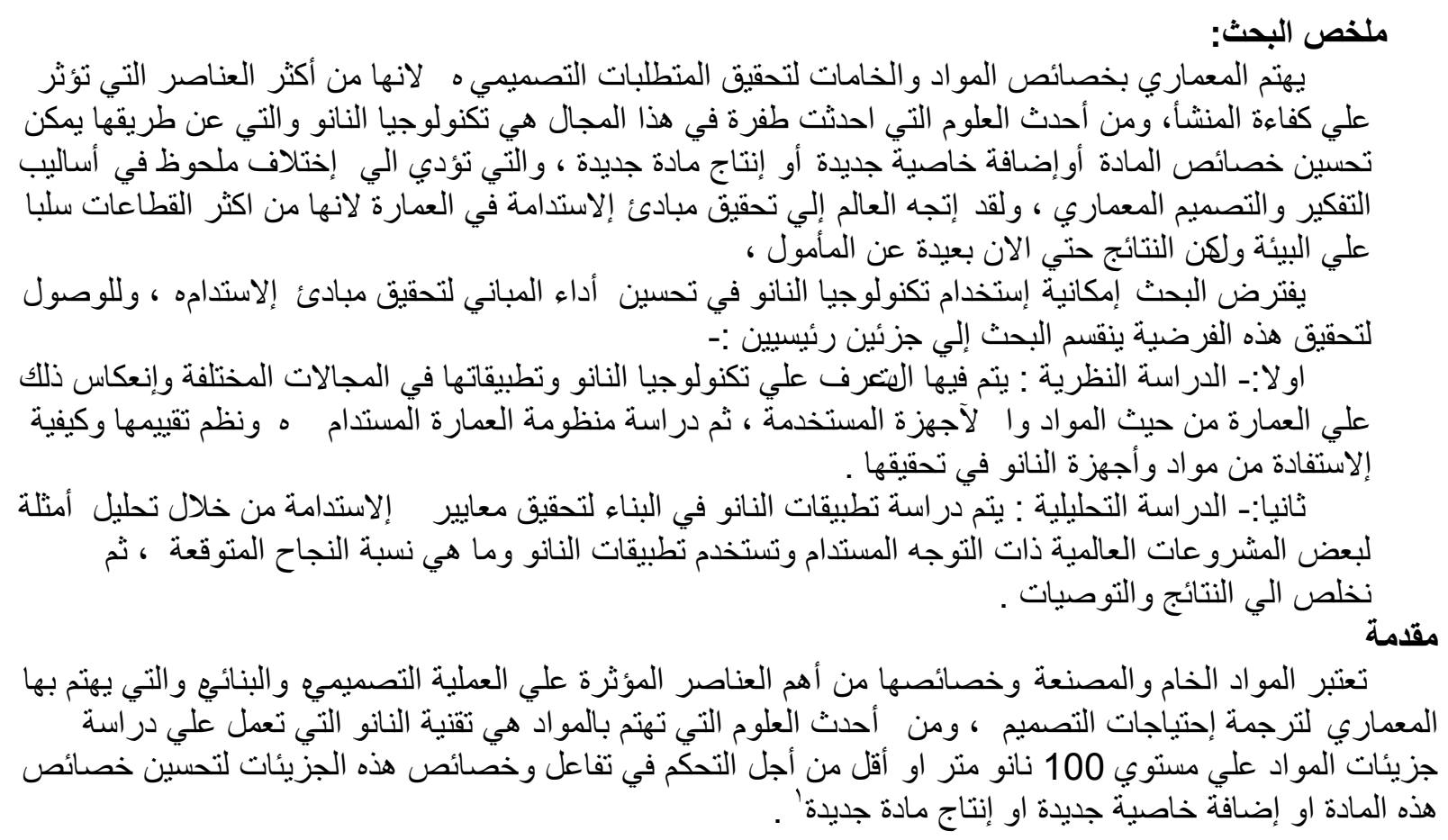


وتساعد هذه الإمكانيات الجديدة المعماري علي تطوير العملية التصميمية و الوصول بالبناء إلي تحقيق الاستدامة المطللوبة في كل مر احله.

الاشكالية

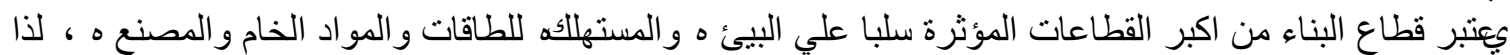

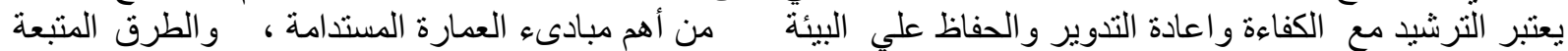

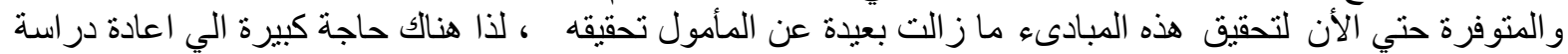

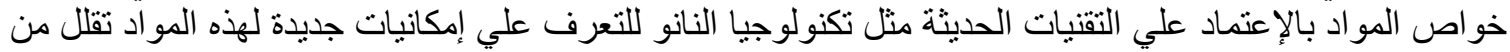
فرضية المردود السلبي لها في مجال البناء وتحقق الإستدامها.

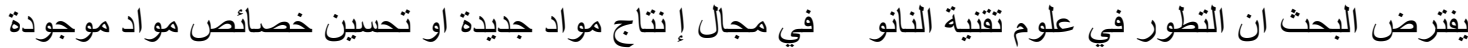

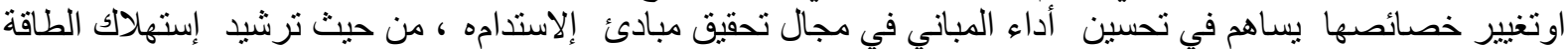
و إلاستفادة من الطاقات المتجددة وترشيد و إعادة إستخدام المياه وتنقية الهو اء للبيئة الداخلي. الهداف البحث

نحاول في هذه الدر اسة استخدام امكانيات تكنولوجيا النانو في تحقيق مبادئ الاستدامة وذلك من خلائ فلال:

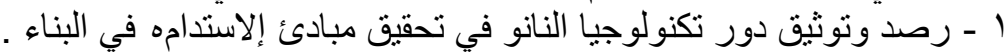

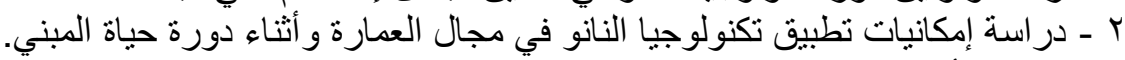

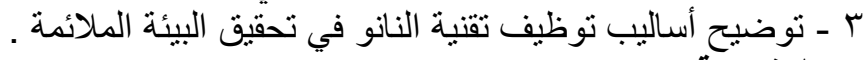

الكملات المفتاحية تقنية النانو - مواد النانو ـ العمارة المستقلية ـ العمارة المستدامه ـ أجهزة النانو.

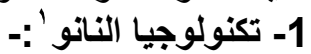

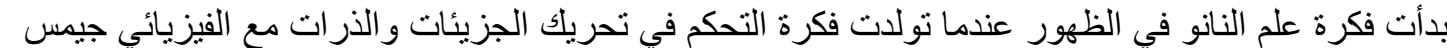

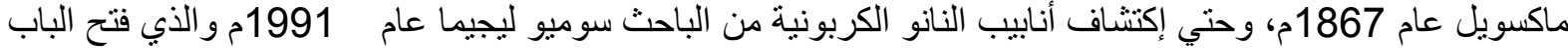

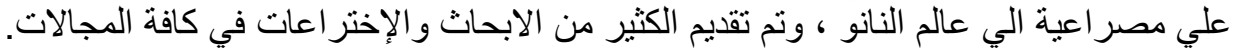

النانو كلمة يونانية بمعني القزم ويستخدم بانه البادئ لاي وحدة مثل الثانية و المتر،ومقياس النانو هو النانومتر وهو

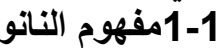
جزء من المليار من المتر او 10 -10 مترمة

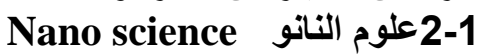

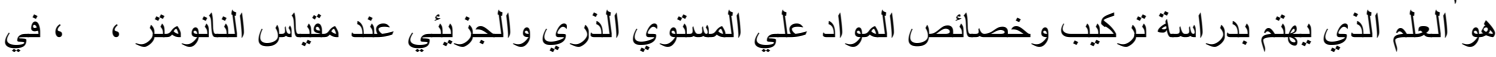

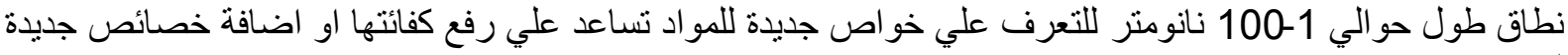

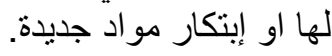

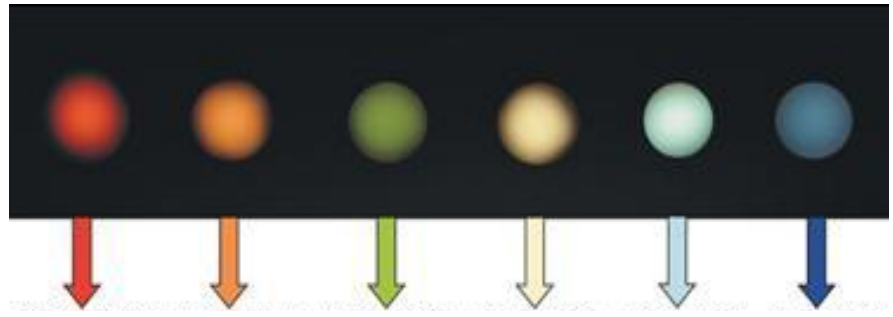

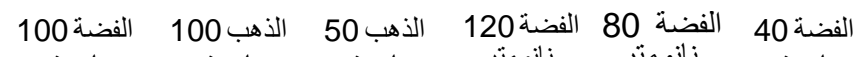

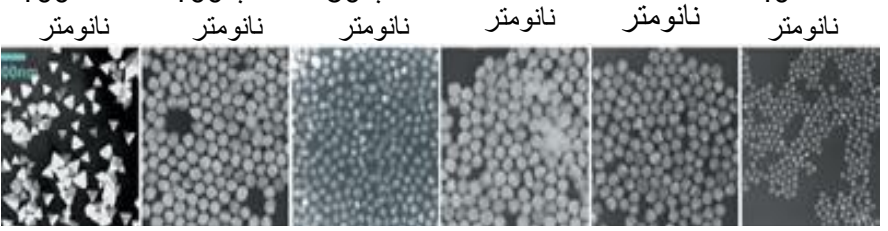

شكل (1) الأثكال المختلفة لجزيئات الفضة والذهب بمقياس النانو

المصدر : بتصرف الباحث

http://szou.cos.ucf.edu/outreach/webpage/Page383.htm 3-1 - 3نوجيا النانو

عرفته هيئة النانو الأمريكية للعلوم و الهندسة

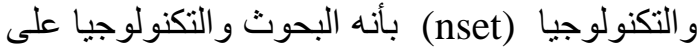
المستويات الذرية و الجزيئية ، في نطاق طوليه لئ حو الي ولي

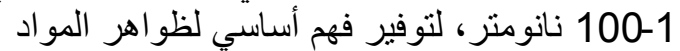

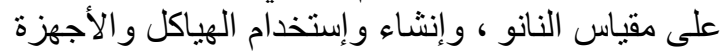

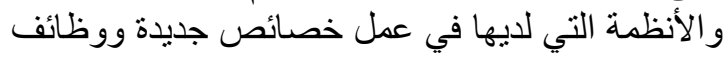

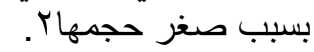
وهي تعتمد علي مسألتين:

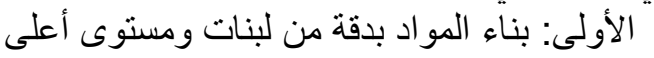

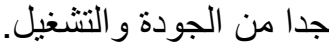

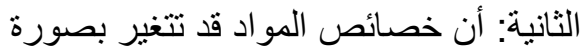
مدهثة عندما تتجز أ الى قطع أصغر الصغ فئر

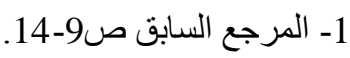

\footnotetext{
${ }^{2}$ Leydecker, Sylvia: Nano Materials in architecture, Interior architecture and Design, Birkhauser.ch ,BaselBoston.Berlin ,2008, p12-13
} 
• يث وجد إن جزيئات المو اد أقل من 100 نانومتر في الحجم يمكن أن تظهر خواص كيميائية وفيزيائية غير

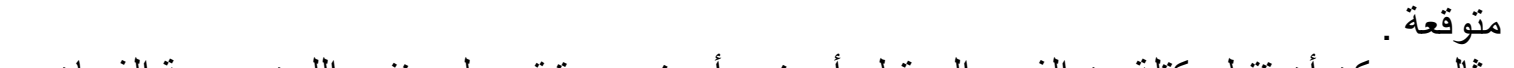

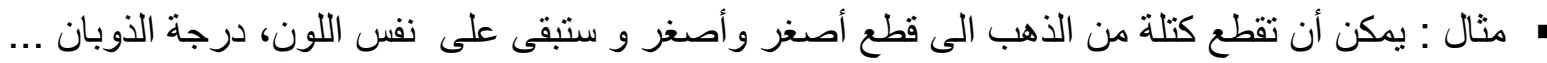

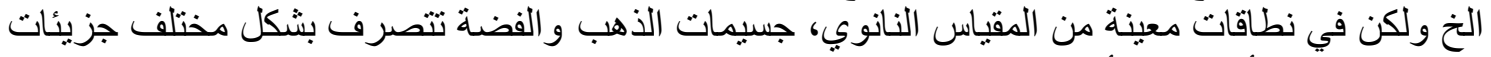

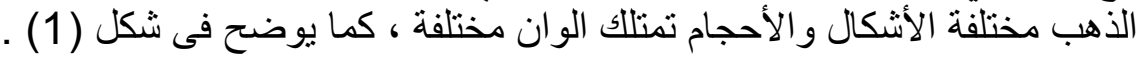

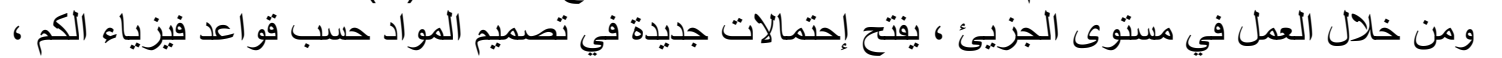

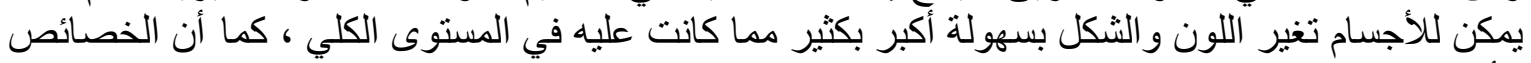

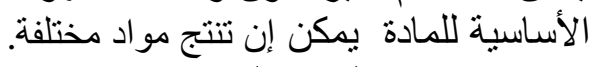

\section{Principles of Nanotechnology 1-3-1}

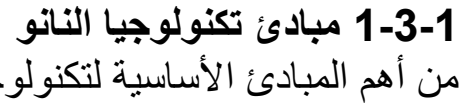

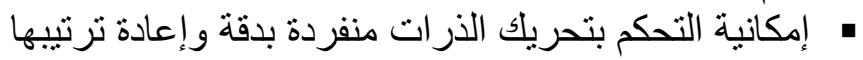

• الخصائص الفيزيائية و الكيميائية للمادة عند مقياس النانو تختلف تباتئ عن خصائص نفس المادة عند مقياسها الطبيعى. هإمكانية التحكم بالذرات فى صنع المو اد والآلات وتتقيتها من الشو ائب وتخليصها من العيوب والتي تؤدي - - إمكانية بناء أى مادة لآن الذرة هى وحدة البناء لكل المواد.

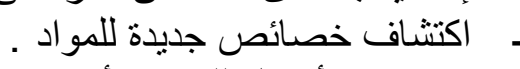

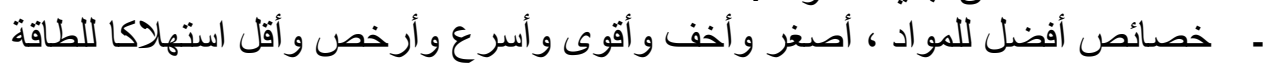
Nanotechnology Application 2-1

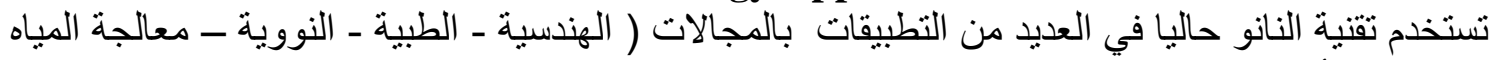

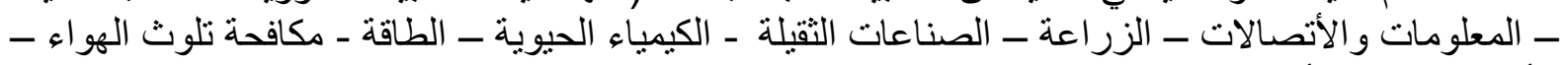
الأغذية ) ، ومن أهم المجالات و التي لها علاقة مباثرة بالعمارة هي التطبيقات التي لها علاقة بالبيئة و الطاقة

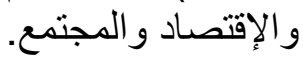

Nanotechnology Application In environment 1-2-2-1 تطبيقات تكنولوجبا النانو فى مجال البيئة

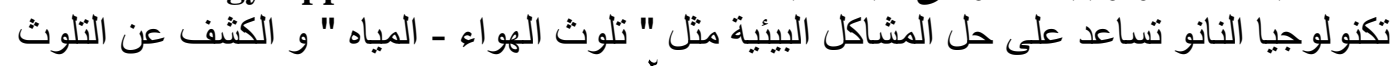

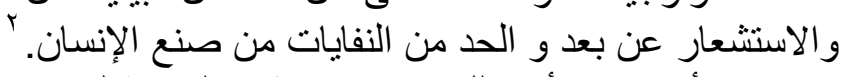

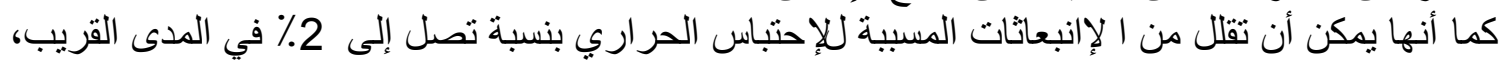

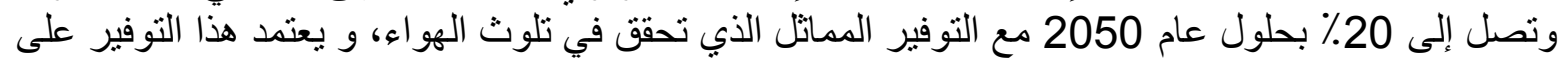

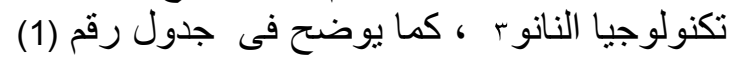

' نهى علوى الحبشى: ما هى تقنية النانف ، مكتبة الملك فهد الوطنية ، جدة ، يوليو 2011، ص (15).

${ }^{2}$ H.dosch-M.H.Van de voorde: Gennesys White Paper, Max Planck Institute for Metallforschungh Stuttgart, 2009

${ }^{3}$ Michel Berger: Nanotechnology's potential to reduce greenhouse gases, 2007,

site: http://www.nanowerk.com/spotlight/spotid=2225.php 
جدول(1) تطبيقات تكنولوجيا النانو للحد من ملوثات البيئة

\begin{tabular}{|c|c|}
\hline القيمة المضافة للحد من الغازات المسببة للاحتباس & المواد الملوثة للبيئة \\
\hline 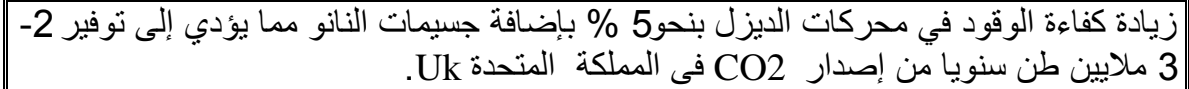 & المواد المضافة للوقود \\
\hline التقليدية في تكاليف إنتاج الخلايا الثُمسية وتعديل أدائها ليصل لخمس مرات أكثر إنتاجية من الخلايا & الخلايا الشمسية \\
\hline 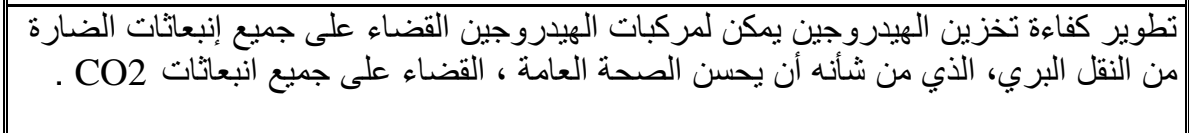 & $\begin{array}{r}\text { The H } \\
\text { Eco }\end{array}$ \\
\hline 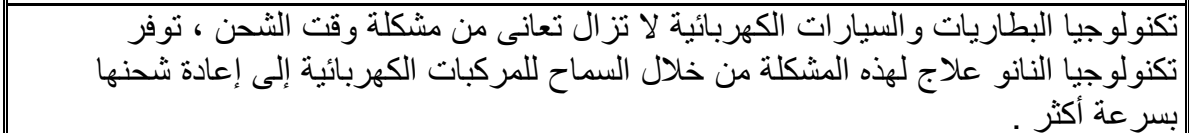 & $\begin{array}{l}\text { البطاريات و المكثفات } \\
\text { Batteries and Super } \\
\text { capacitors }\end{array}$ \\
\hline 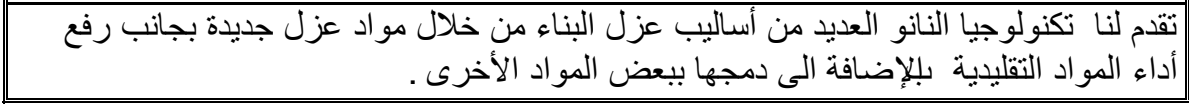 & 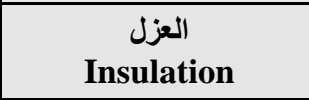 \\
\hline
\end{tabular}

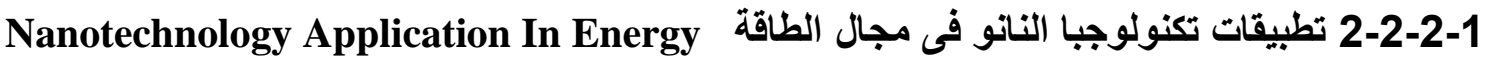
توفر تكنولوجيا النانو إلامكانات الأساسية لتحسين وتطوير كل من مصادر الطادئ الطاقة التقليدية (الوقود الحفرى

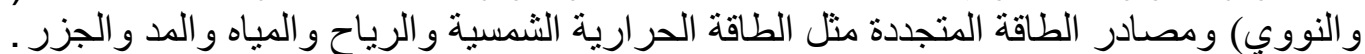

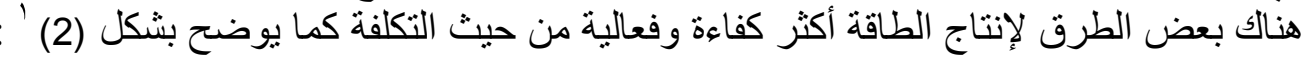

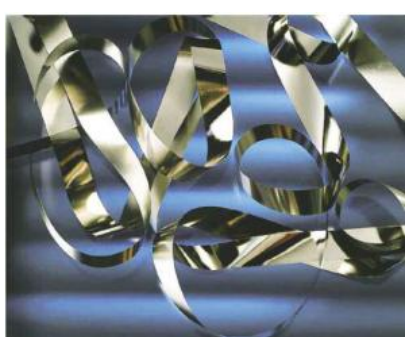

شر ائح أنابيب النانو

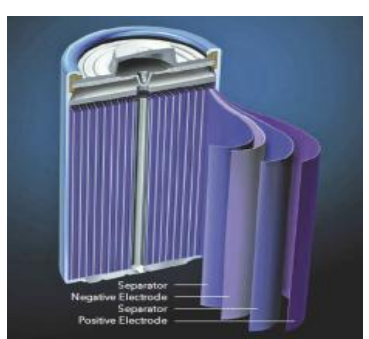

بطاريات ليثيو أيون

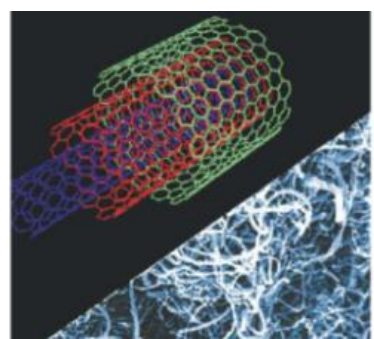

طواحين الهواء المصنوعة من أنابيب النانو الكربونية

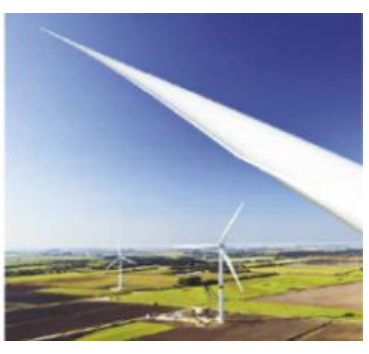

شكل (2) بعض طرق أنتاج الطاقة بفضل تكنولوجيا النانو

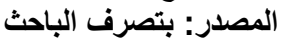

http://www.hessen-nanotech.de/mm/NanoEnergy_web.pdf

* زيادة الكهرباء التي تولدها الطواحين الهو ائية: باستخدام انابيب النانوية الكربونية لصنع ريش طو احين الهواء.

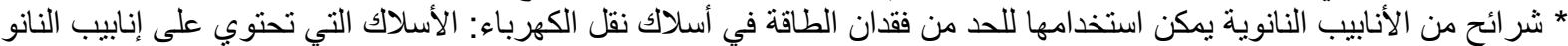
الكربونية وخفض تكلفة الخلايا الثمسية.

* تحسين أداء البطاريات وتحسين الكفاءة و الحد من تكلفة خلايا الوقود.

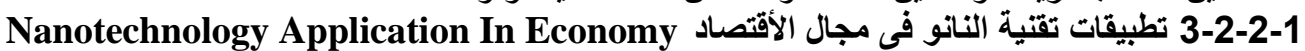

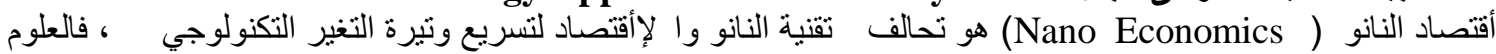

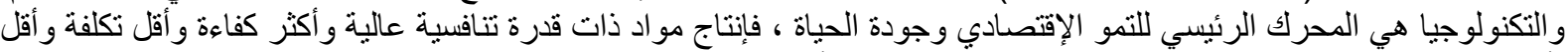

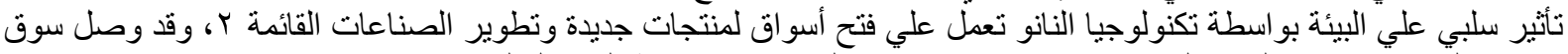

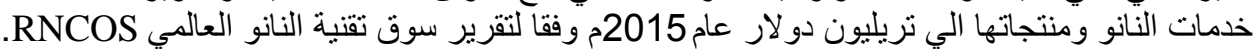

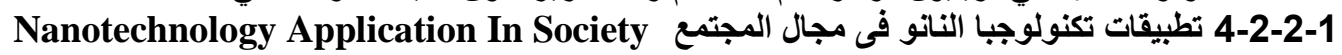

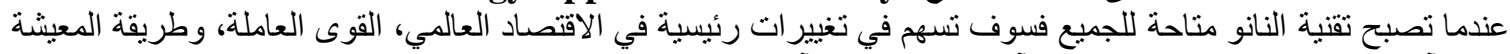

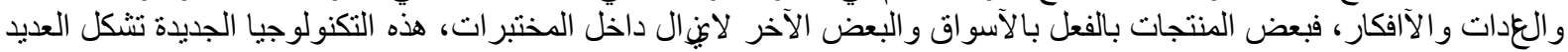

1 Hessen Nanotech: Application of Nanotechnologies in the Energy sector, Hessian ministry of economy, transport, urban and development, Germany, volume9, 2008.p 30-40-49.

${ }^{2}$ Edward Cupoli: The Relationship Between Nanotechnology and Economics, 2010,p1-3

Site": http://www.azonano.com/article.aspx?ArticleID=2545 


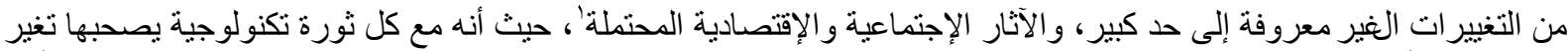
في عادات الأفر اد والوظائف اليومية والحياة الإجتماعية وبالتالي يمكن ان تتغير الفر الاغات المعمارية المعروفة من ناحية الوظيفة أو

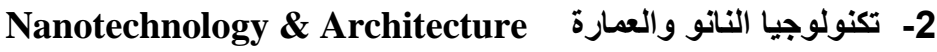

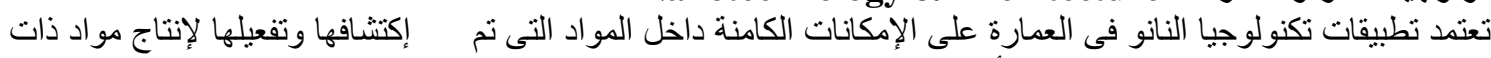

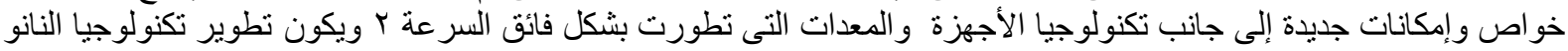

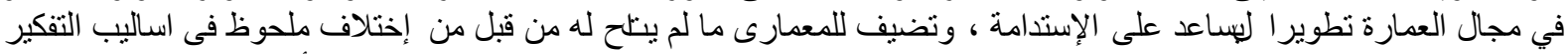

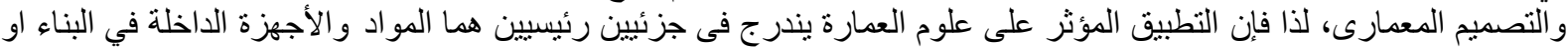

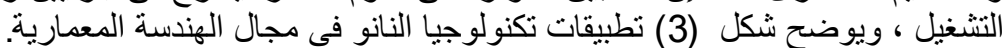

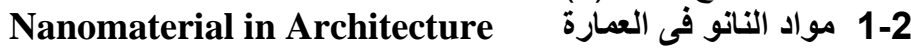

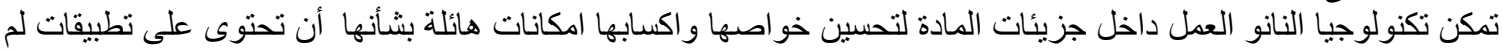

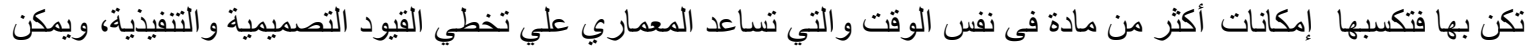
تصنيف مو اد النانو كما بلى فئي:

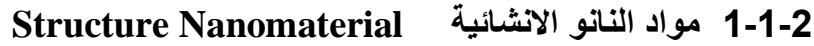

تتيح لنا تكنولوجيا النانو تطوير وتحديث الانية المو اد الانشائية الاساسية وهي الحديد والخرسانة و إستحداث مو اد إنشائية نستعرضها مثل انانيب النانو الكربونية.

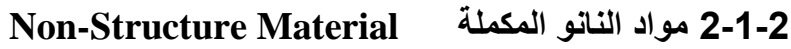

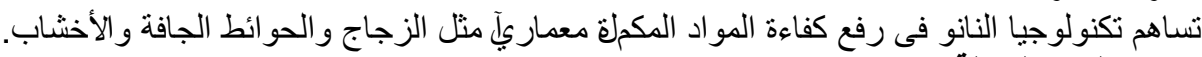

insulation material 3-1-2

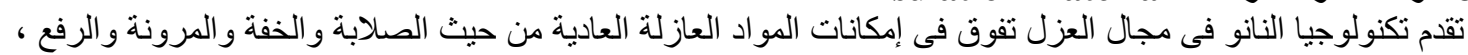

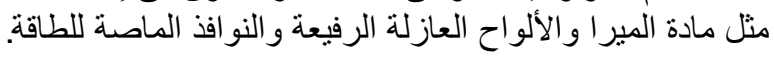

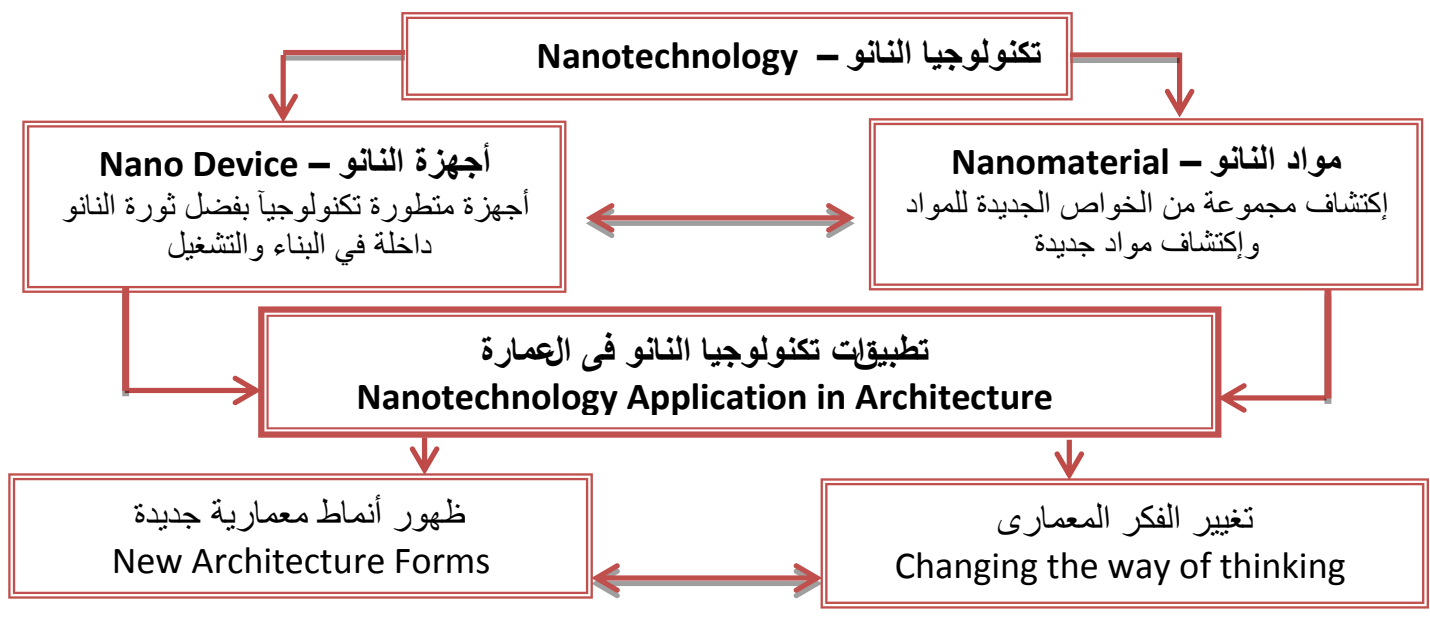

شكل (3) تأثير تكنولوجيا النانو على مجال العمارة

المصدر : بتصرف من الباحث

Dr. George Elvin. Nanotechnologv for Green Building (2007). p1- 11

Nano-Coating الطلاعات النانونية 4-1-2

الطلاء ياخذ مساحة كبيرة من أبحاث تكنولوجيا النانو لتحقيق مجموعة واسعة من الخصائص مثل سهولة التظظيف وذاتية

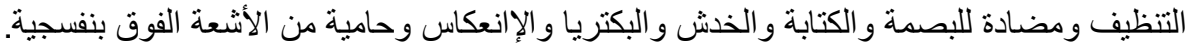

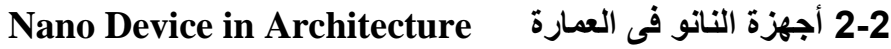

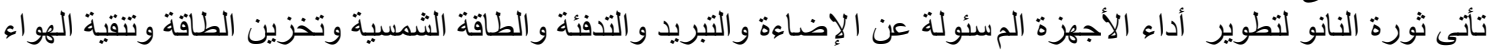

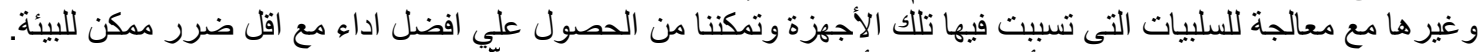

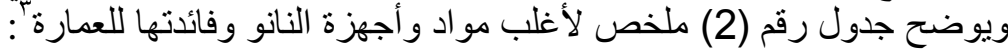

\footnotetext{
${ }^{1}$ Nanotechnology \& Society: introduction at the university of California, centre of nanotechnology society,2010, site: http://www.cns.ucsb.edu/about/nanotechnology-society

${ }^{2}$ Nanotechnology In Architecture site $: \underline{\text { http://greendimensions.wikidot.com/nanotechnology-in-architecture }}$

3 Dr. George Elvin, Nanotechnology for Green Building,2007,p 1-88
} 
دور تطبيقات تقنية النانو في تحقيق العمارة المستدامه

جدول (2) تطبيقات تكنولوجيا النانو علي العمارة بتصرف من الباحث

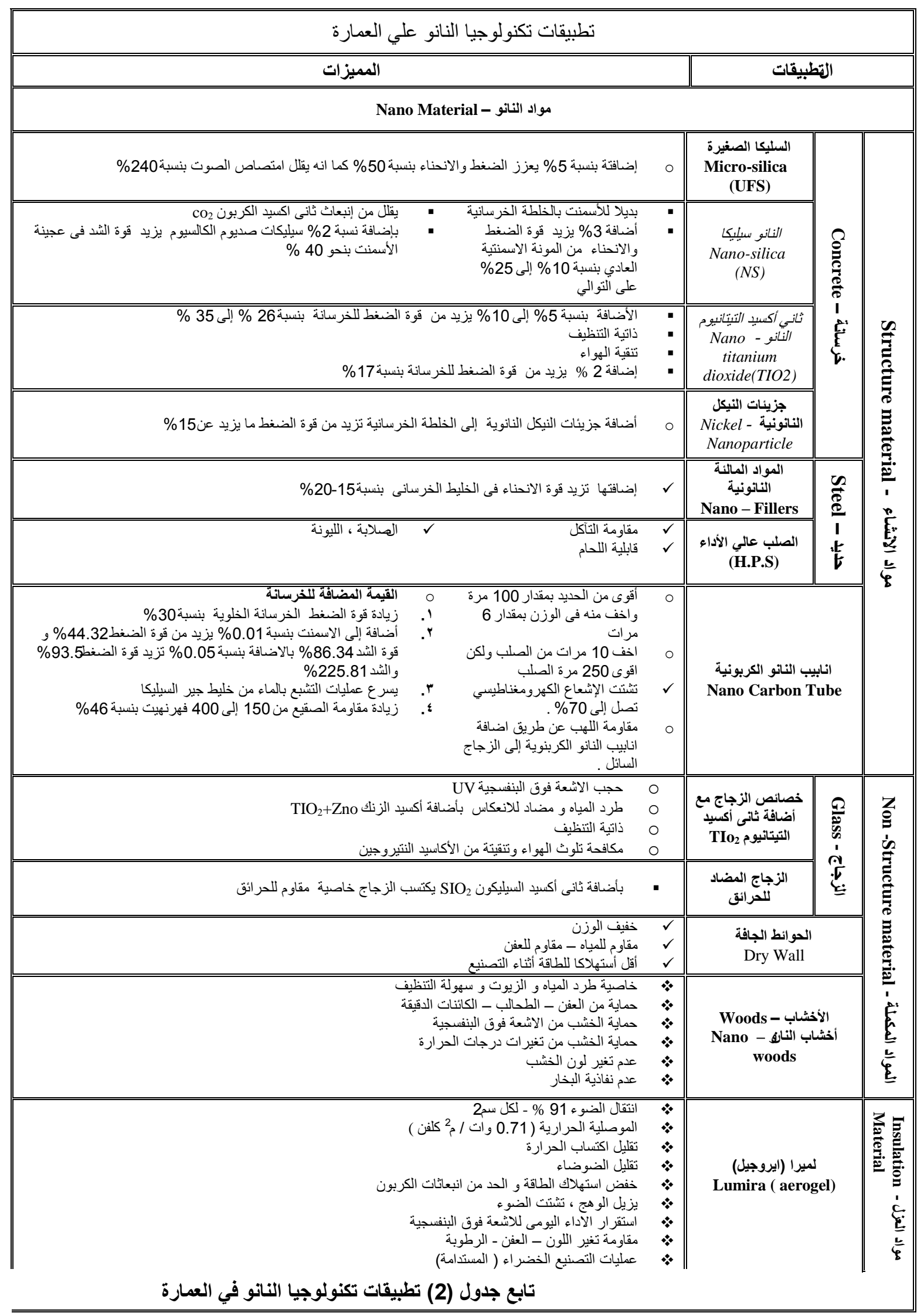


دور تطبيقات تقنية النانو في تحقيق العمارة المستدامه

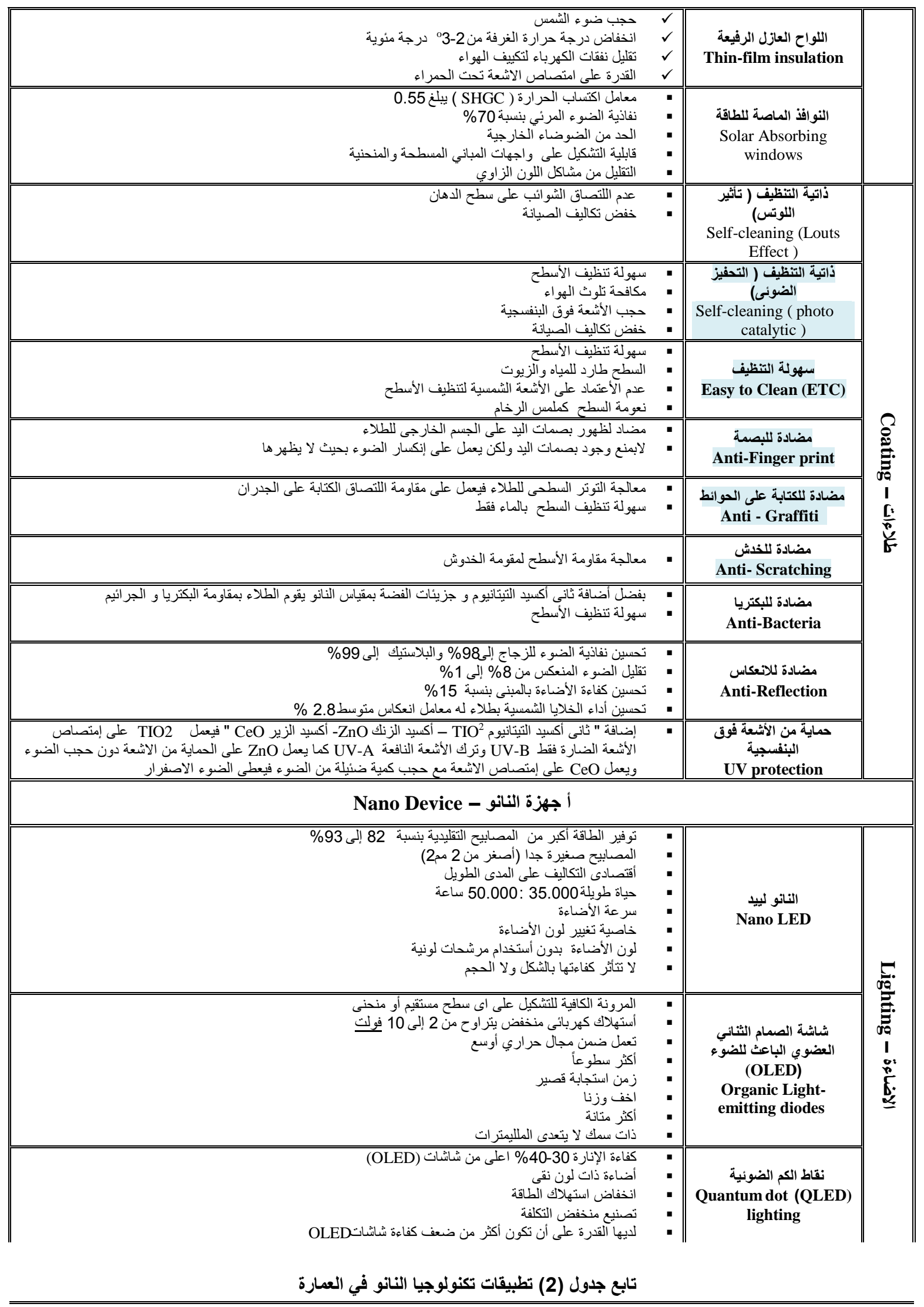




\begin{tabular}{|c|c|c|c|}
\hline 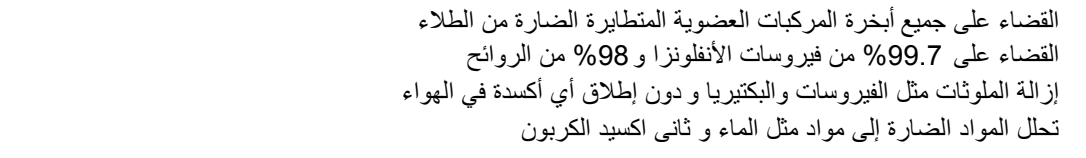 & $\begin{array}{l}\not \\
0 \\
\checkmark \\
\checkmark\end{array}$ & $\begin{array}{l}\text { تنقية الهواء في الأماكنة } \\
\text { المغلقة } \\
\text { Indoor Air } \\
\text { Purification }\end{array}$ & \multirow{2}{*}{ 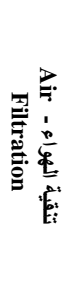 } \\
\hline الأكقاسية الهو المنطايرة الخارجى تكون بأساس من خاصية التحفيز الضوئى فيتم القضاء على ما بين 20\% و 80\% من الملوثات و & $\circ$ & $\begin{array}{l}\text { تنقية الهواء الخارجى } \\
\text { Outdoor Air } \\
\text { Purification }\end{array}$ & \\
\hline 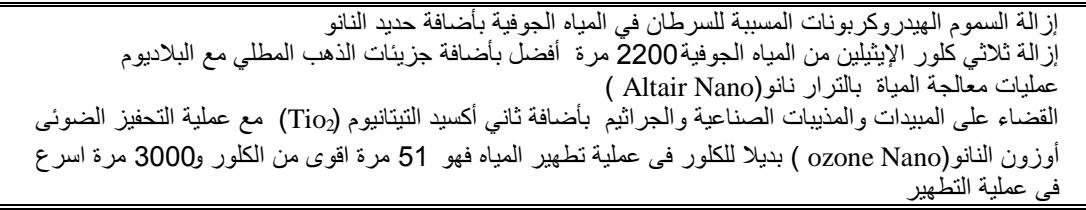 & $\begin{array}{l}\checkmark \\
\checkmark \\
\checkmark \\
\checkmark \\
\checkmark\end{array}$ & تنقية المياة & \\
\hline 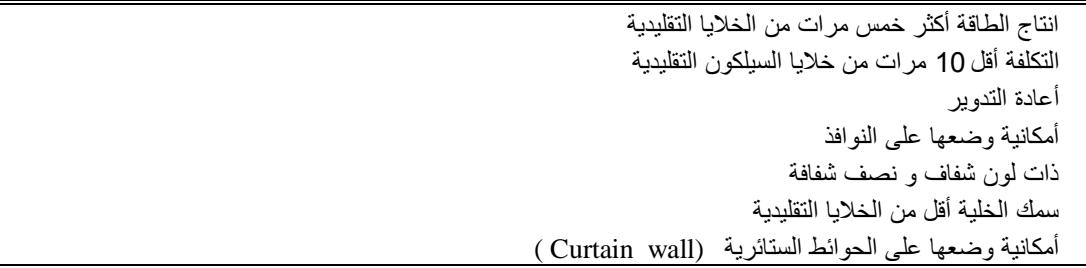 & 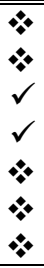 & خلايا السليكون الشمسية & 象 \\
\hline 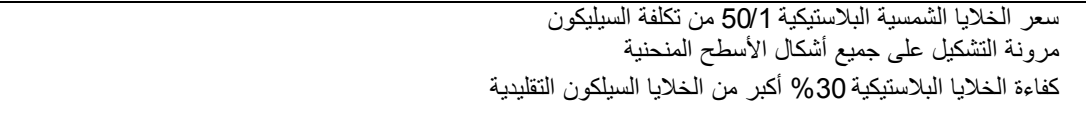 & $\begin{array}{l}\circ \\
\circ \\
+\end{array}$ & $\begin{array}{l}\text { خلايا الاغثية الرقيقة } \\
\text { Thin-film solar }\end{array}$ & E: \\
\hline 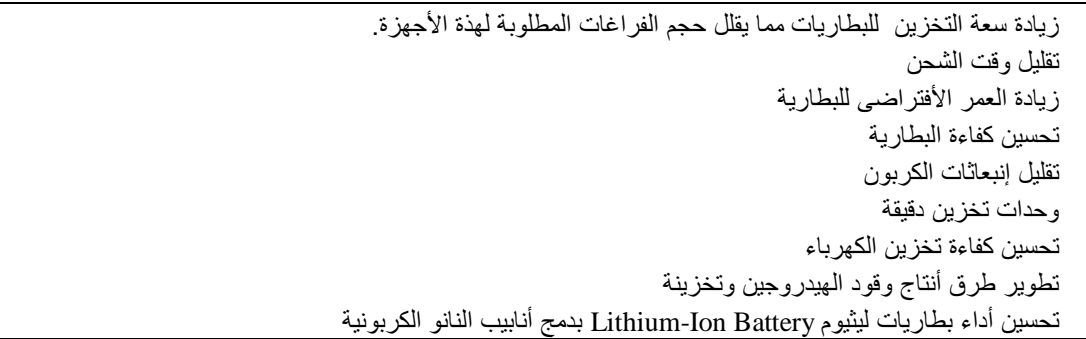 & $\begin{array}{l}\checkmark \\
\checkmark \\
\checkmark \\
\checkmark \\
\checkmark \\
\checkmark \\
\checkmark \\
\checkmark \\
\checkmark\end{array}$ & لطاقة - Storage Energy & تخزين \\
\hline
\end{tabular}

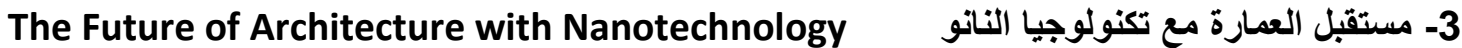

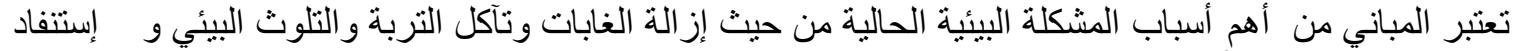

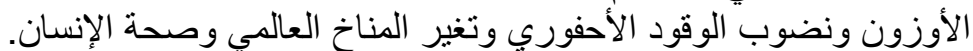
وستقود ثورة تكنولوجيا النانو إلى على علاج هذه المشكلة من خلال تحقيق الاستدامة البيئية والاقتصادية و الاجتماعية ، حيث

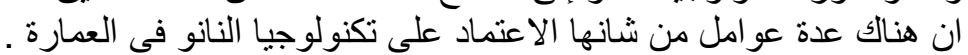

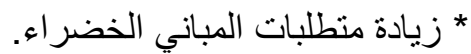

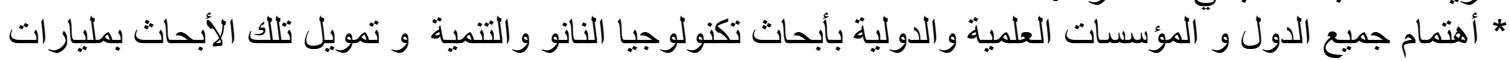

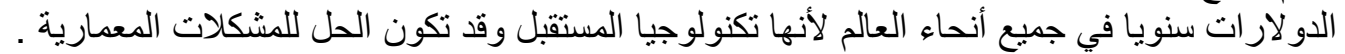

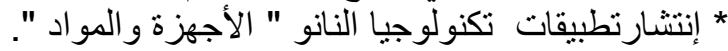

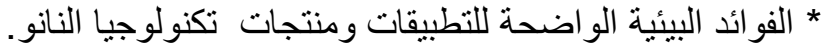
* * انخفاض تكاليف التكنولوجيا مع مرور الوقت. دلالات الرموز مو اد متو اجدة بالأسو اق العالمية 


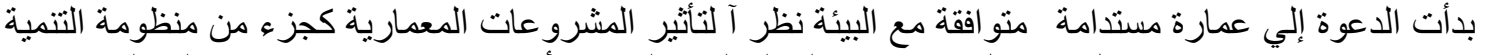

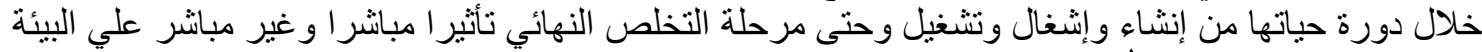

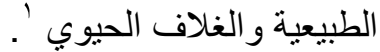

وما يلي بعض مظاهر تأثير المشروعات المعمارية علي البيئة الطبيعية والموضحة بالثكل (4):

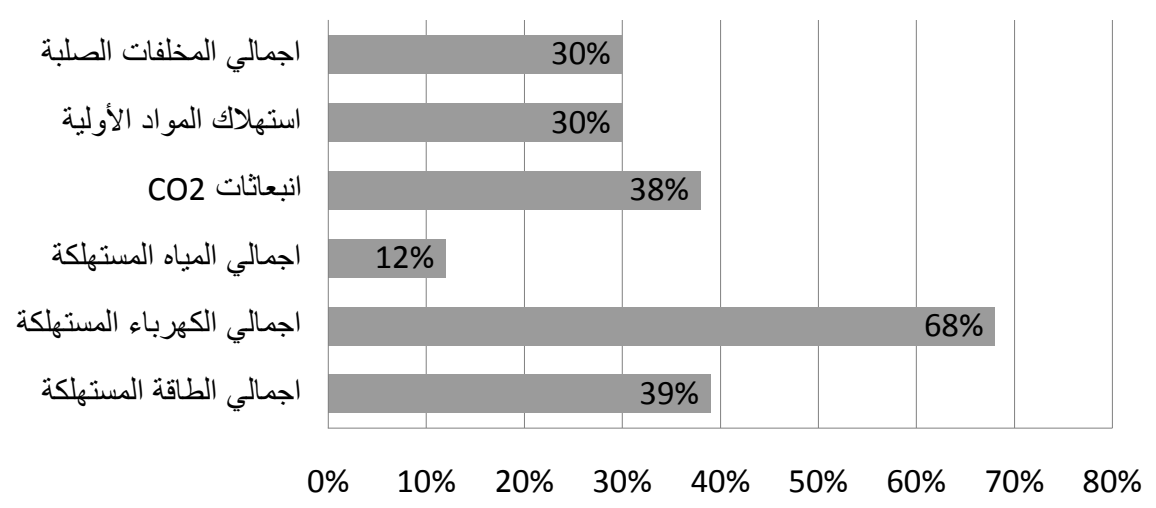

\section{شكل (4) تأثير قطاع الإنثاء علي البيئة - الولايات المتحدة الامريكية \\ http://www.wbdg.org/design/sustainable.php - المصدر: بتصرف البانئ}

تكتمل منظومة العمارة المستدامة † ج بتحقيق مبادئ ومعايير الاستدامةعن طريق تطبيق مبادىء العمارة

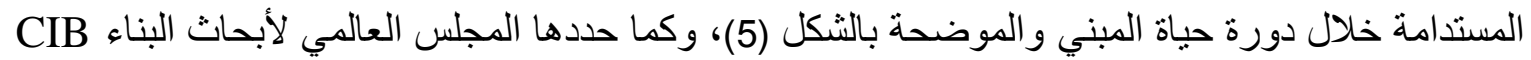
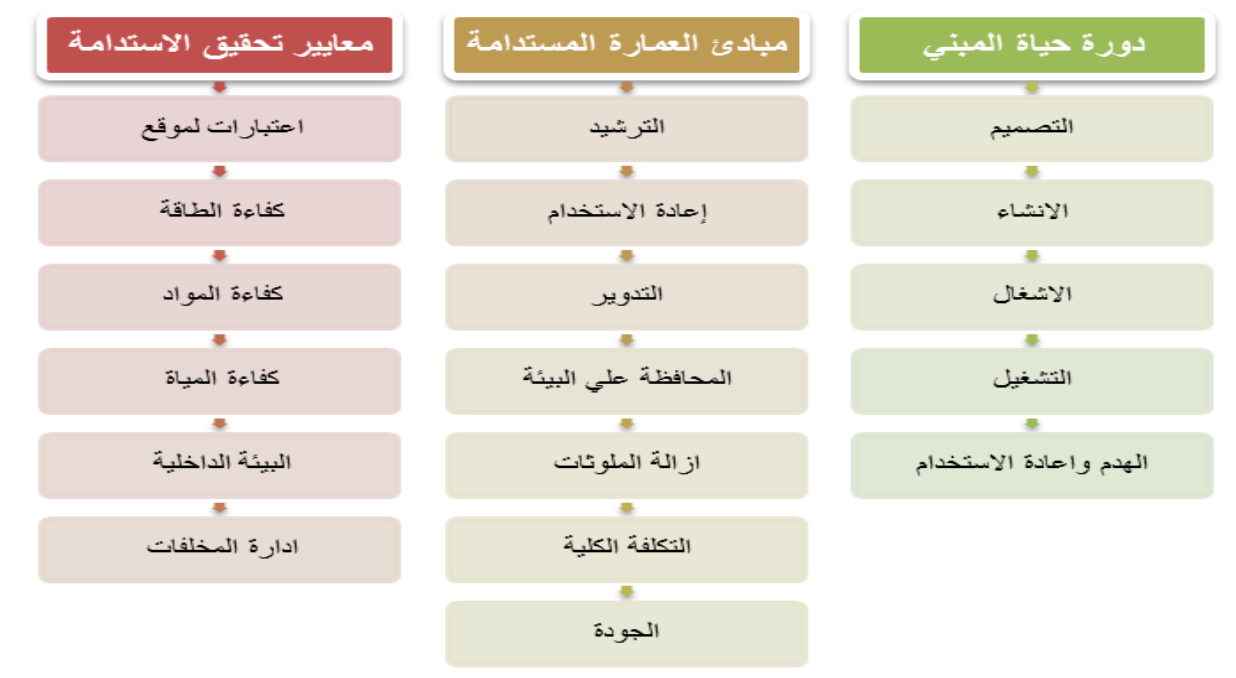

شكل (5) منظومة تحقيق العمارة المستدامة المصد

1-4 أنظمة تقييم المباني المستدامة:

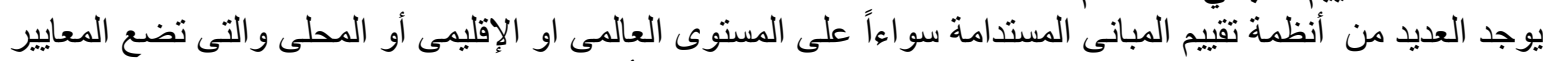

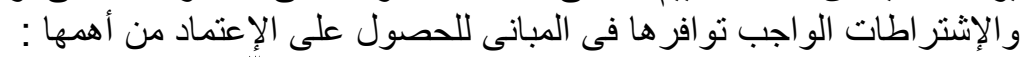

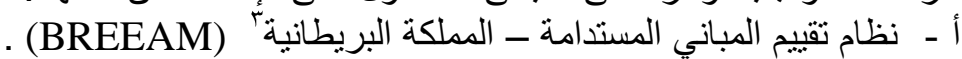
ب ـ نظام تقييم المباني المستدامة - الو لايات المتحدة الأمريكية' (LEEDTM).

${ }^{1}$ National Institute of Building Sciences, Whole Building Design guide, site: http://www.wbdg.org/design/sustainable.php .

${ }^{2}$ William Brister: Sustainable green Architecture .2007, site: http://ezinearticles.com/?Sustainable-GreenArchitecture\&id $=715327$

${ }^{3}$ The Building Research Establishment Environment Assessment Method, site: http://www.breeam.org, Accessed (13-8-2014) 


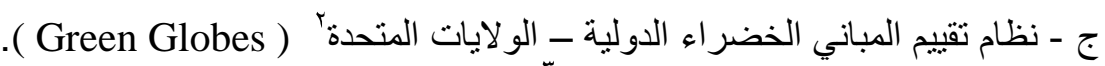

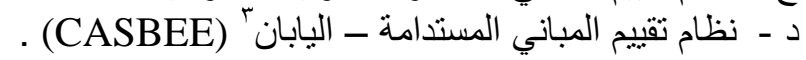

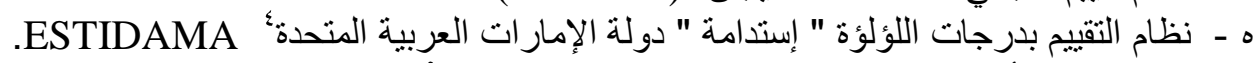

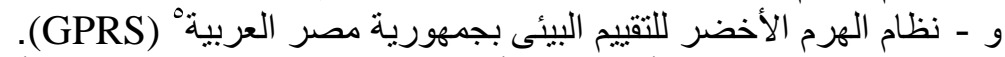

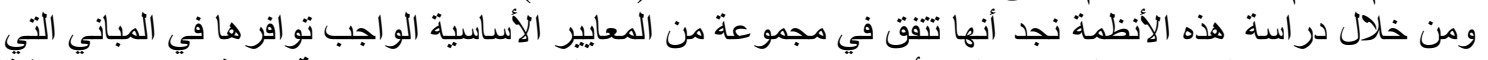

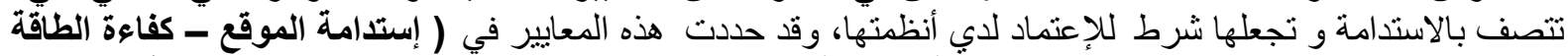

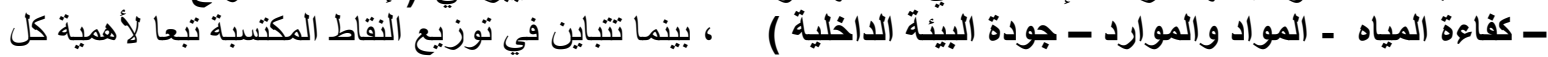

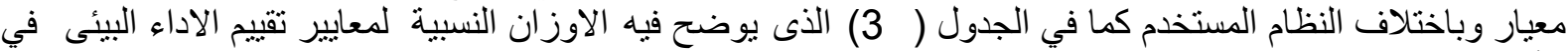

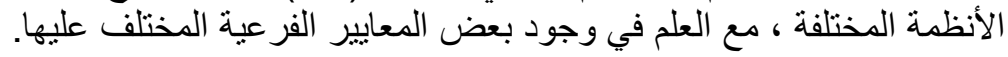

جدول (3) متوسط الاوزان النسبية لانظمة تقييم الاداء البيئي المصدر : تصرف الباحث لألمان

\begin{tabular}{|c|c|c|c|c|c|}
\hline جودة البيئة & المواد والموارد & كفاءة المياه & كفاءة الطاقة & استدامة الموقع & انظمة تقييم الاداء \\
\hline$\% 15$ & $\% 12.5$ & $\% 6$ & $\% 19$ & $\% 10^{\prime \prime}$ & BREEM \\
\hline$\% 22$ & $\% 19$ & $\% 7$ & $\% 25$ & $\% 20$ & LEED \\
\hline$\% 20$ & $\% 10$ & $\% 8.5$ & $\% 38$ & $\% 11.5$ & Green Globe \\
\hline$\% 20$ & $\% 15$ & $\% 2$ & $\% 20$ & $\% 15$ & CASBEE \\
\hline$\% 21$ & $\% 16$ & $\% 24.2$ & $\% 24.8$ & $\% 6.7$ & ESTIDAMA \\
\hline$\% 10$ & $\% 10$ & $\% 35$ & $\% 25$ & $\% 5$ & GPRS \\
\hline$\% 18$ & $\% 14$ & $\% 14$ & $\% 25$ & $\% 11.5$ & متوسط الأنظمة \\
\hline
\end{tabular}

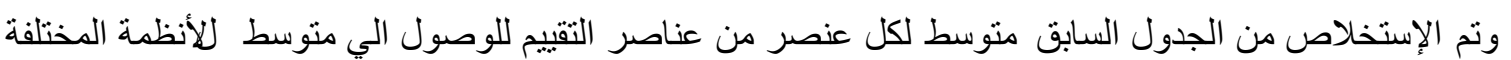

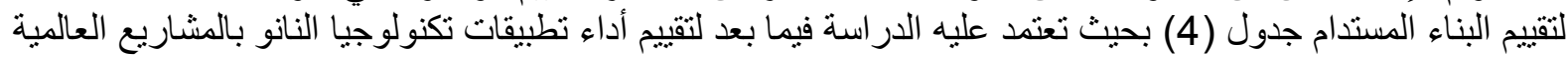
و المشاريع التجريبية للار اسة.

جدول (4) النسب المئوية لمتوسط أنظمة التقييم المستدام

\begin{tabular}{|c|c|c|c|c|c|c|}
\hline مجموع الدرجات & $\frac{\mathfrak{T}}{\underline{\xi}}$ & 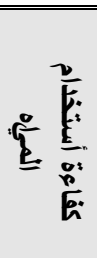 & $\begin{array}{l}\underline{\underline{\underline{E}}} \\
\underline{\underline{E}} \\
\underline{\underline{E}} \\
\underline{\underline{E}}\end{array}$ & 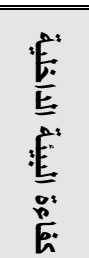 & 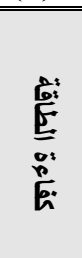 & معايير الإستدامة \\
\hline 82.5 & 11.5 & 14 & 14 & 18 & 25 & متوسط أنظمة التقييم للبناء \\
\hline$\% 100$ & \%14 & $\% 17$ & $\% 17$ & $\% 22$ & $\% 30$ & النسب المئوية للتئوسط أنظمة المستام \\
\hline
\end{tabular}

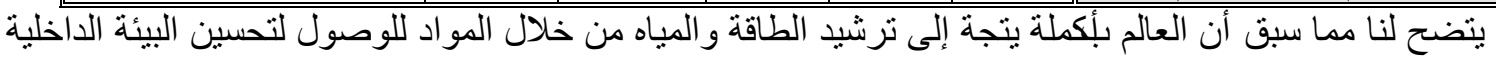

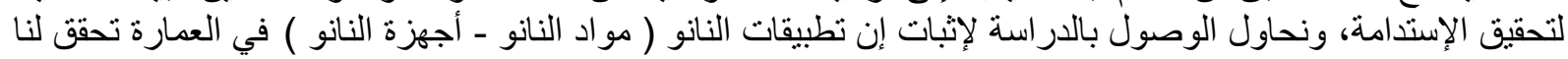
ذلك.

الاراسة التحليلية:-

${ }^{1}$ Leadership in Energy and Environmental Design Green Building Rating System, site : http://www.usgbc.org/leed Accessed (13-8-2014)

${ }^{2}$ Green Globes-Building Environmental Assessments, site: http://www.greenglobes.com , Accessed(13-8-2014)

${ }^{3}$ Comprehensive Assessment System For Building Environmental Efficiency (CASBEE), Site : http://www.ibec.or.jp/CASBEE/english/ Accessed (13-8-2014)

${ }^{4}$ Abo Dhabi Urban Planning " Estidama(2010), site, http://www.estidama.com Accessed(15-8-2014)

${ }^{5}$ Establishment of Egyptian Green Building Council " GPRS" : Egyptian Green Pyramid Rating System

"Version 0.1" , site, http://egyptgbc.org/EGBC_Presentation/EGBCfinal.pdf accessed (20-8-2014) 
5- منهجية تحقيق معايير الاستدامة من خلال تطبيقات النانو:

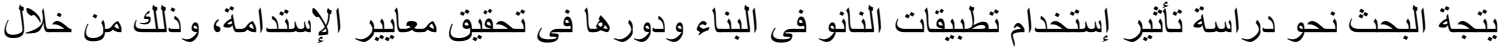
در اسة تحليلية لأمثلة مختارة من المشرو عات المستقبلية العالمية جاري تنفيذها أو سيتم تتفيذها ذات التئ التوجه المستدام و التىى

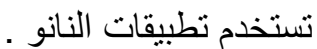

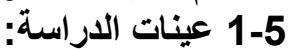

تم اختيار ثلاث مشرو عات منها ما تم الإنتهاء من تتفيذه ومنها ما هو مقترح تنقفيذه في الآعو ام القادمة.

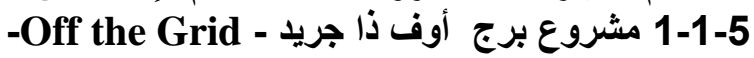

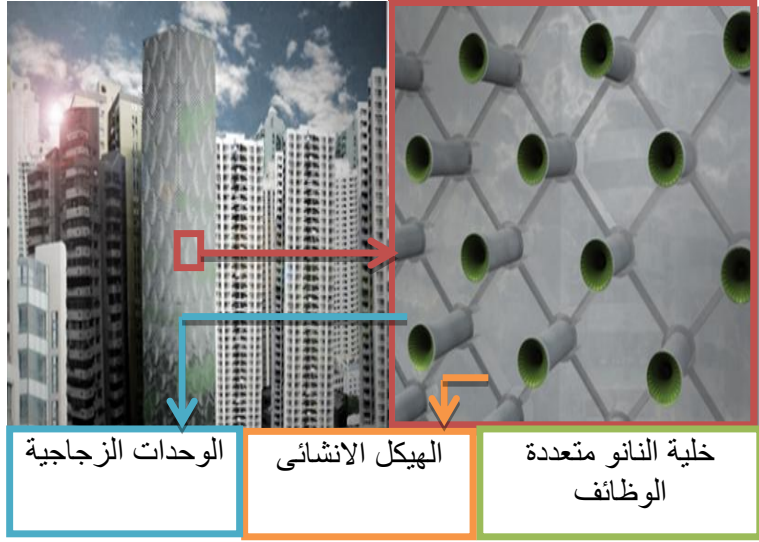

(Off the Grid : Sustainable Habitat 2020 ) (6كل (6) Source: Off the Grid: Sustainable Habitat 2020, http://www.yatzer.com/1095_off_the_gridsustainab le_habitat_2020

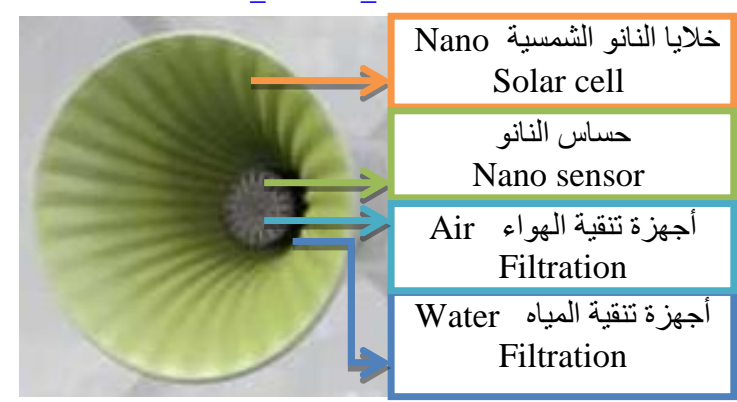

شكل (7) مكونات خلية النانو متعددة الوظائف

r كامل
Philips's مشروع سكني من تصميم المكتب المعماري

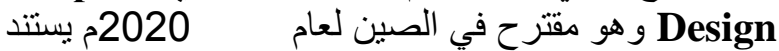
المشروع على تطوير الإسكان المستدام من خلامل تطبيقات

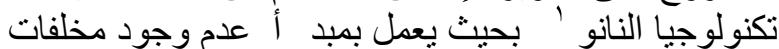

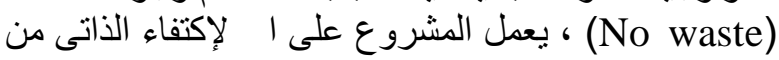

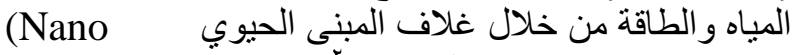

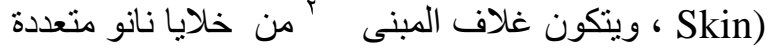

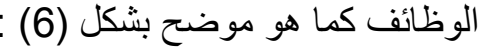
1-1-1-5 خلايا النانو متعددة الوظائف:

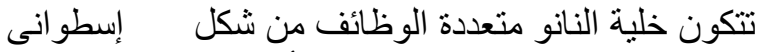

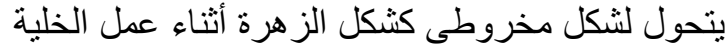

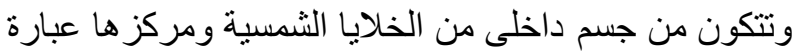

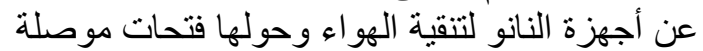

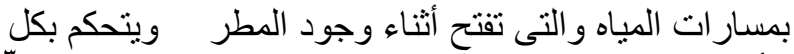

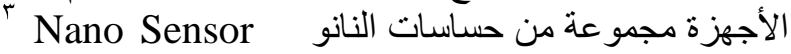

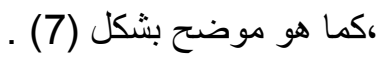

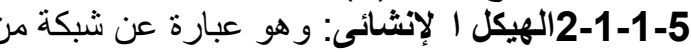

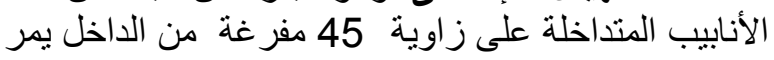

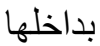
أ ـ أسلاك النانو التى تنقل الكهرباء المولدة من الخلايا الثمسية النان ب أنابيب نقل مياه الأمطار إلى خز انات المياه ج ـأنابيب نقل الهواء بعد عملية تنقيته إلى للفر اغان التياه الداخلية حسب رغبة مستخدم الفراغ الداخلى.

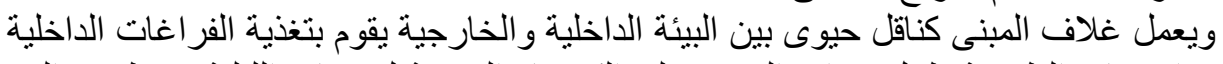

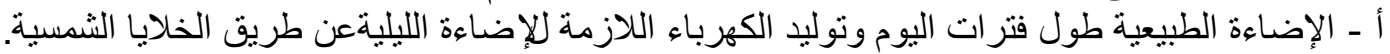

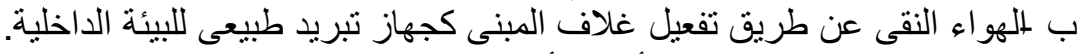

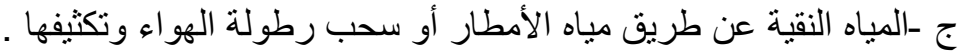

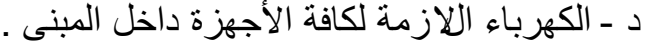

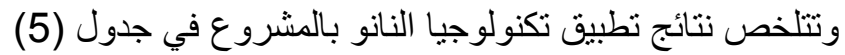

${ }^{1}$ PROBLEM: POLLUTION / SOLUTION: SUSTAINABLE HABITAT 2020, http://www.popsci.com/environment/article/2010-09/life-edge?page=2\%2C3

${ }^{2}$ Off the Grid: Sustainable Habitat2020 ,video https://www.youtube.com/watch?v=-wmiNhkptQw )

${ }^{3}$ Off the Grid: Sustainable Habitat2020, video https://www.youtube.com/watch?v=-wmiNhkptQw 
جدول (5) نتائج تطبيق تكنولوجيا النانو بمشروع برج أوف ذا جريد المصدر: الباحث

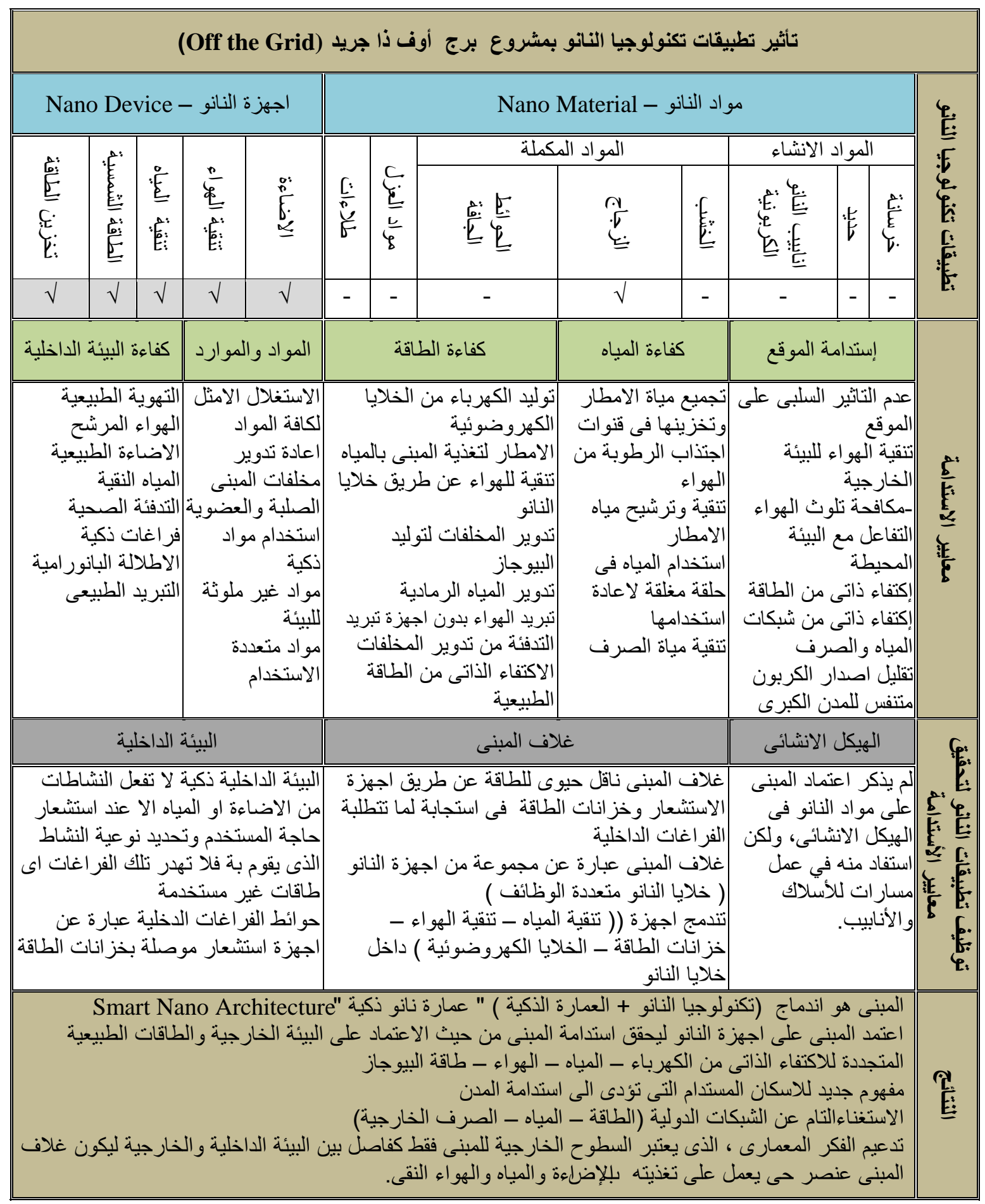




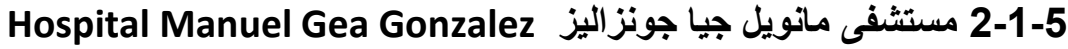

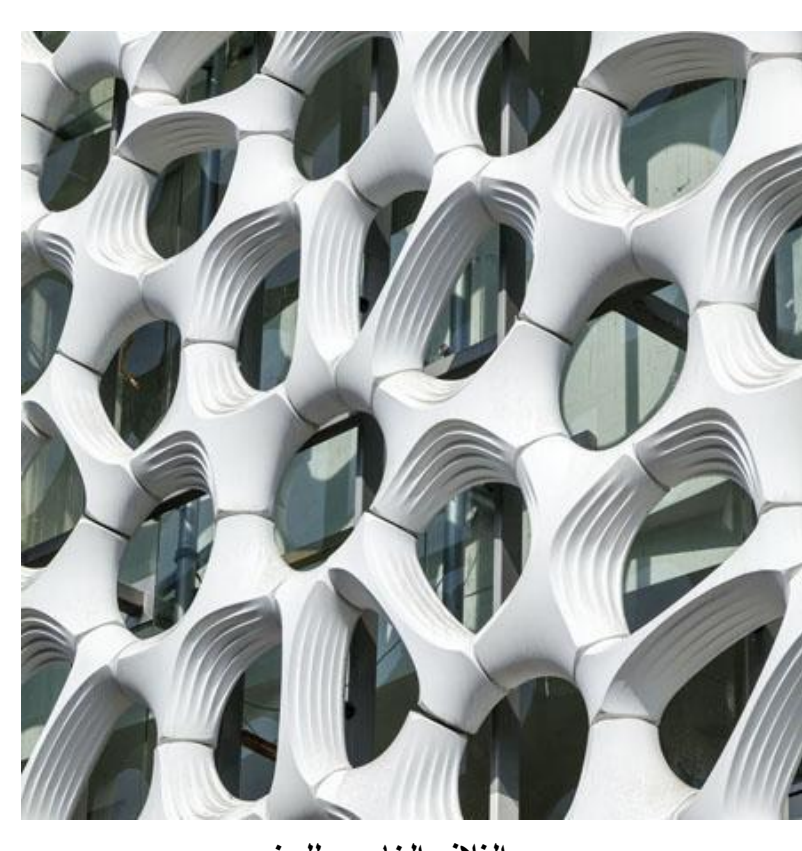

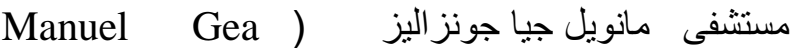
Gonzalez) Allison Dring\& Daniel سيتي و هو من تصميم

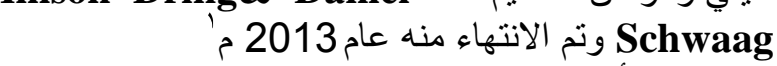
تم الأستعانة بوحدات

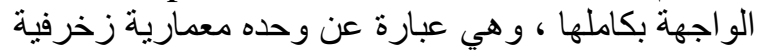

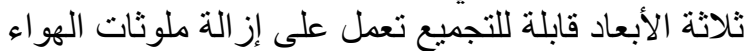

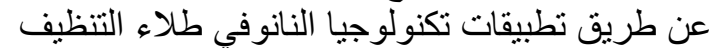

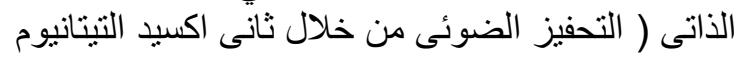

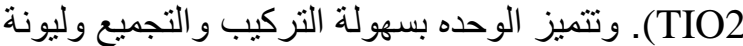

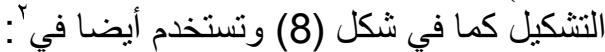

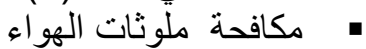

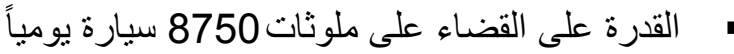

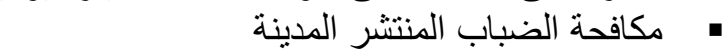
تقليل سرعة الرياح لمعالجة أكبر قدر من الملوثات باللهو اء الإستفادة من كل جو انب الواجهة (Skin) تظليل المبنى لحتفاظ المبنى بدرجات حر الب الورة الارة منخفضة

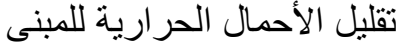

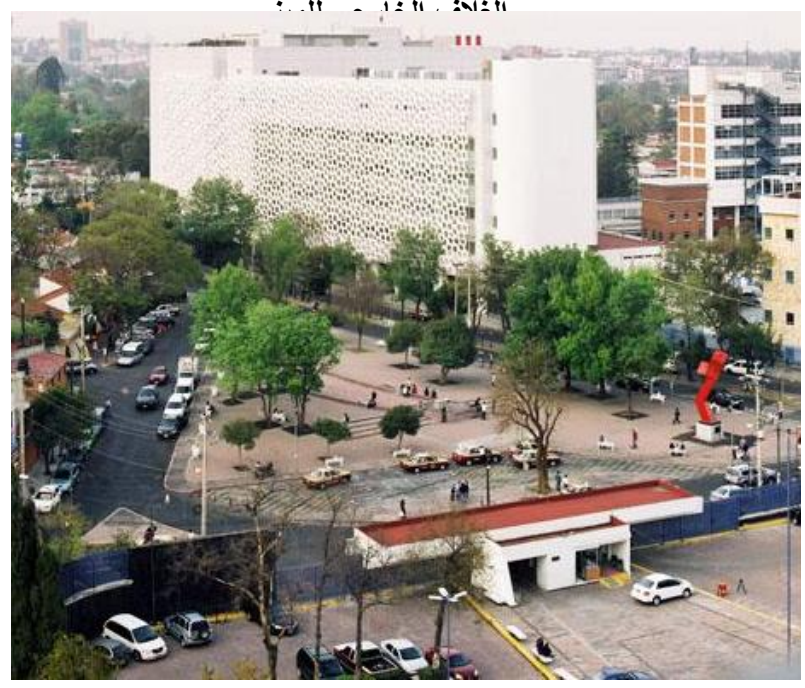
صورة ذهنية مميزة للمبنى الاحمي الئي

وتتلخص نتائج تطبيق تكنولوجيا النانو بالمشروع في جدول

Manuel Gea Gonzalez - شكل (8) مستثفى مانويل جيا جونزاليز

Source: http://www.medicaldaily.com/mexico-cityhospital-eats-pollution-torre-de-especialidadesfeatures-innovate-facade-tiling-265942

\footnotetext{
${ }^{1}$ Torre de Especialidaes , http://www.prosolve370e.com/pr_torre.htm

${ }^{2}$ Mexico City Hospital, http://www.medicaldaily.com/mexico-city-hospital-eats-pollution-torre-deespecialidades-features-innovate-facade-tiling-265942
} 
جدول (6) نتائج تطبيق تكنولوجيا النانو بمشروع مسشتفي مانويل المصدر: الباحث

تأثير تطبيقات تكنولوجيا النانو بمستثفى مانويل جيا جونزاليز Hospital Manuel Gea Gonzalez

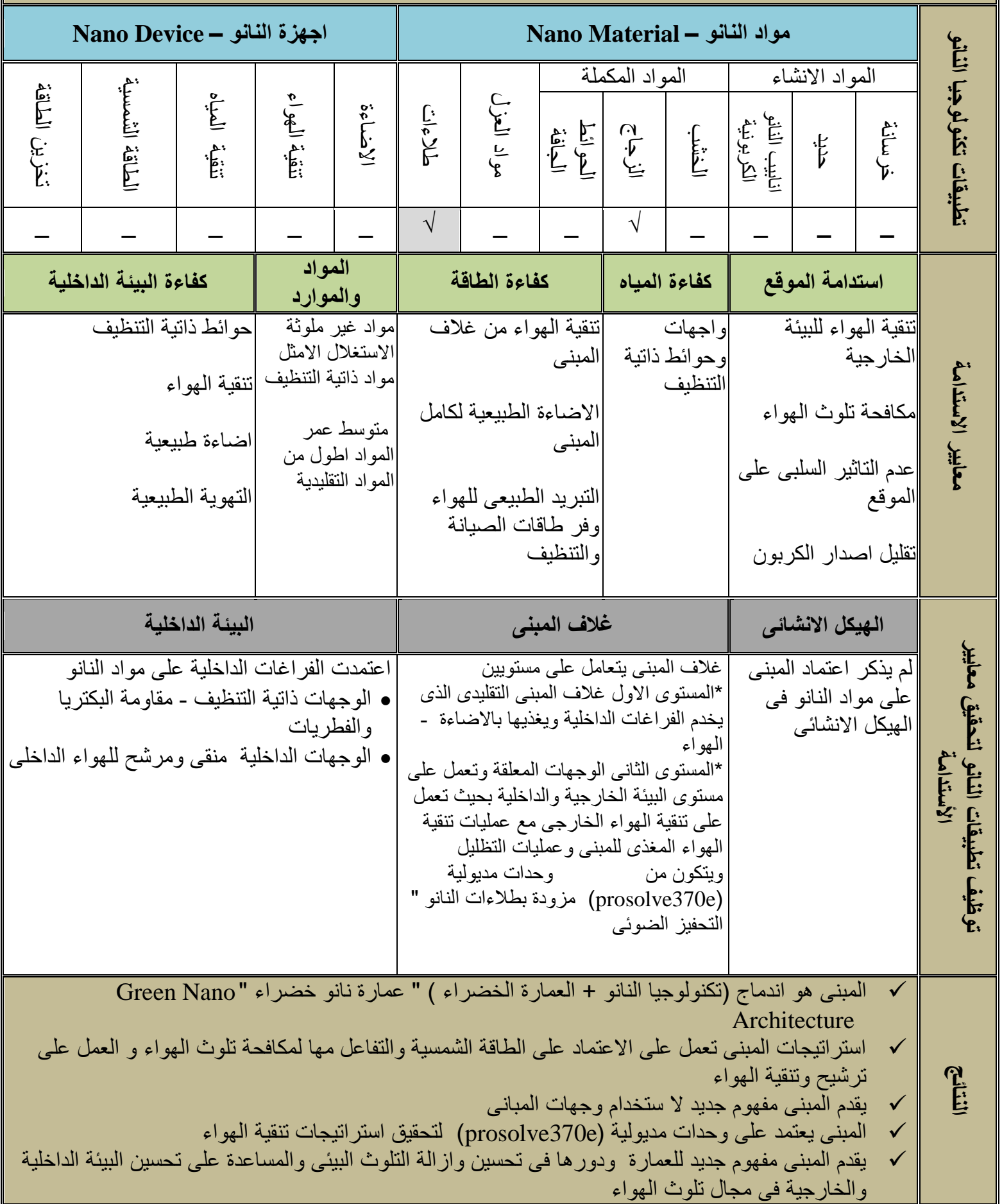


Anti-Smog Tower '3-1-5 برج مضاد الضباب فئم

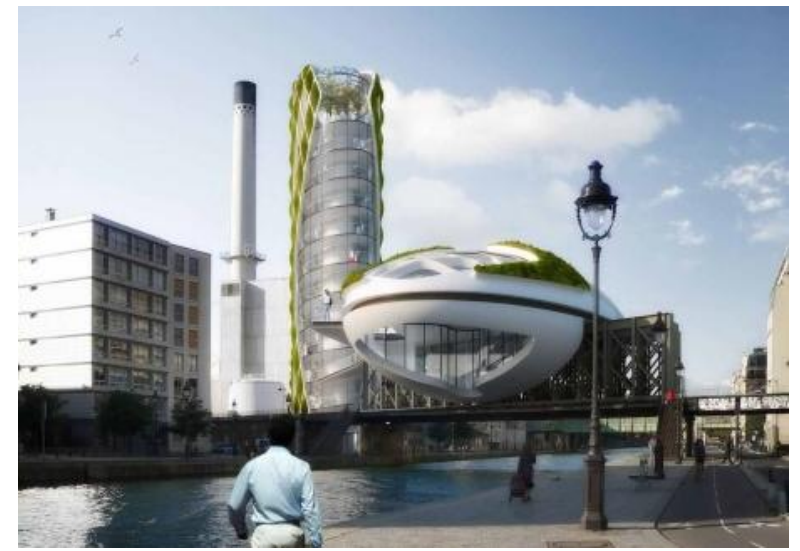

مقتر ح مستقبلي يقع علي القناة المائية دولوكيت في باريس - فرنسا والمعروفة بالضباب الثديد وإرتفاع

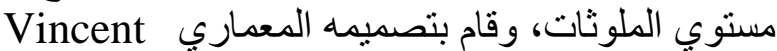

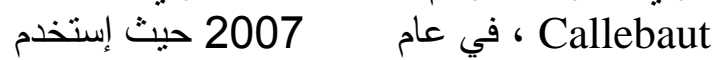
تكنولوجيا النانو لصناعة نموذج مبني مستدام يعتمد

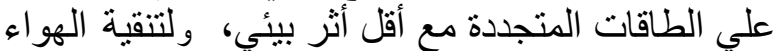

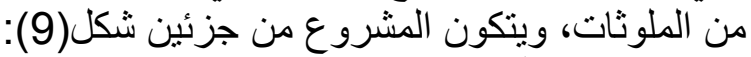

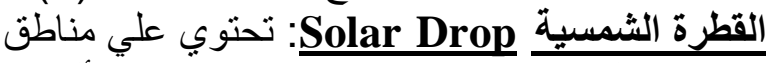
ترفيهية كالحدائق وحمامات السباحة ولة وصالات الألعاب و المحلات التجارية ، وهي عبارة عات عن شكل بيضاوي

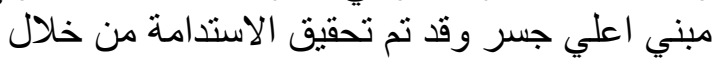
تطبيقات النانو في العناصر الأتية:

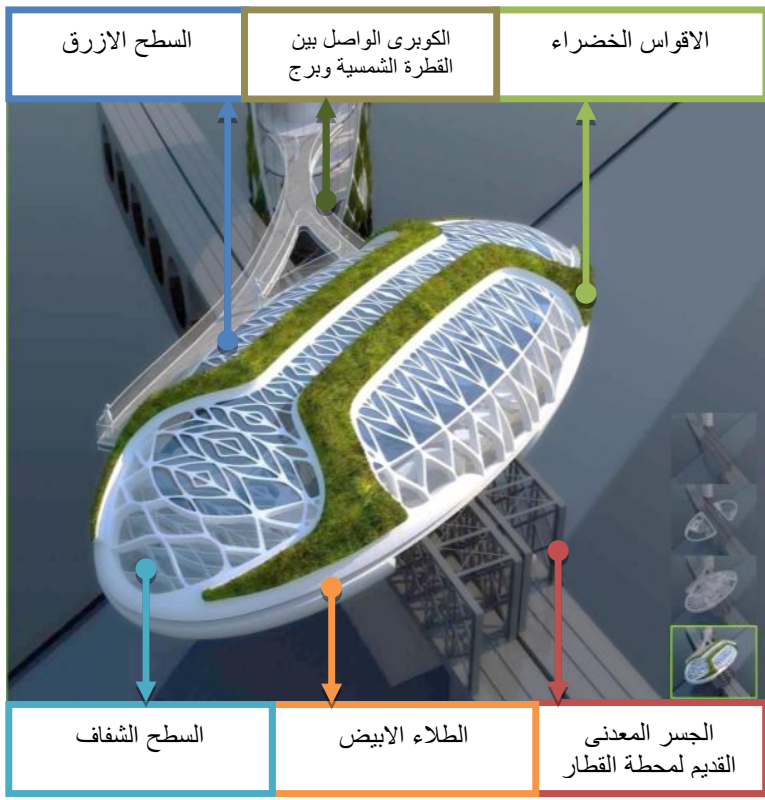

الأجز اء الفعالة بكتلة القطرة الشمسية

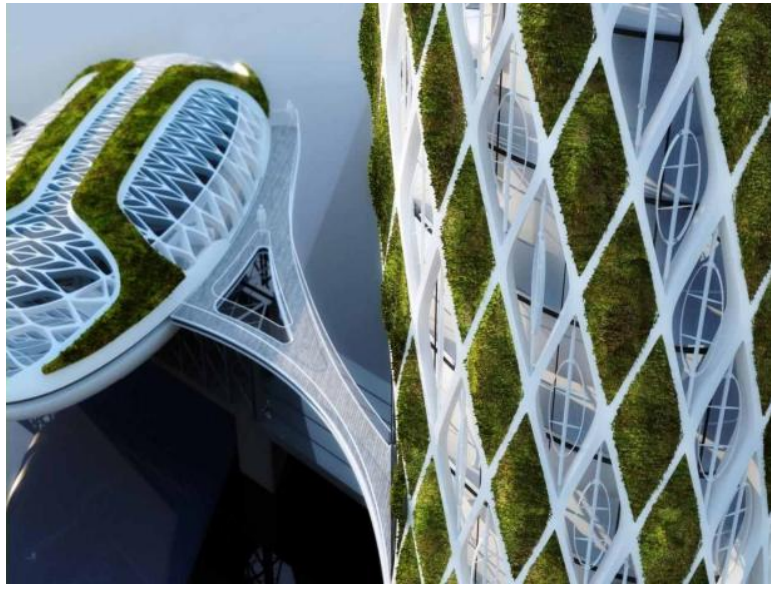

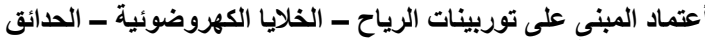
المعلقة - طلاءات التحفيز الضوئي (ثانى اكسيد التياح التيتانيوم

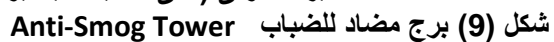

http://inhabitat.com/anti-smog-architecture:المصدي (ون

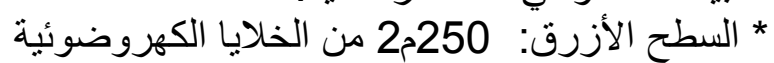
تغطي سطح المبني. * السطح الثفاف:"لتغذية المبني بالإضاءة الطبيعية.

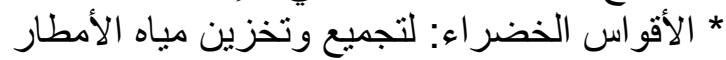

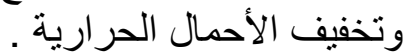
*طلاء النانو الأبيض: ذو خاصية التنظيف الذاتي ومكافحة تلوث الهواء بتحليلها الي مركبات غير لتري

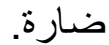

برج الرياح Wind Tower: ويحتوي علي متحف ومعرض ومركز لعلوم الطاقات المتجدة:، وتم استخدام

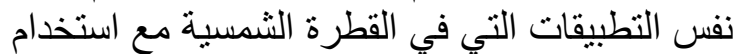

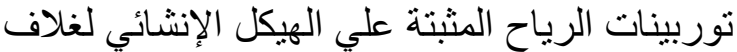

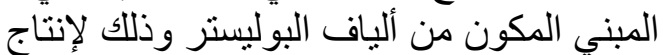
الكهرباء. وتتلخص نتائج تطبيق تكنولوجيا النانو بالمشروع في

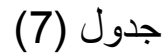

جدول (7) نتائج تطبيق تكنولوجيا النانو بمشروع برج مضاد الضباب المصدر: الباحث

\footnotetext{
${ }^{1}$ http://inhabitat.com/anti-smog-architecture-a-catalyst-for-cleaner-air-in-paris
} 


\begin{tabular}{|c|c|c|c|c|c|c|c|c|c|c|c|c|c|}
\hline \multicolumn{14}{|c|}{ تأثير تطبيقات تكنولوجيا النانو في برج مضاد الضباب Anti-Smog Tower } \\
\hline \multicolumn{5}{|c|}{ اجزة النانو - Nano Device } & \multicolumn{8}{|c|}{ Nano Material - مواد النانو } & \multirow{4}{*}{ 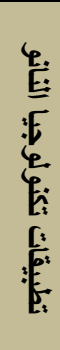 } \\
\hline \multirow[b]{2}{*}{ 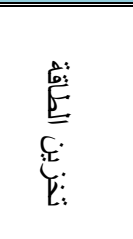 } & \multirow[b]{2}{*}{ 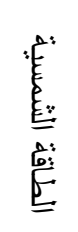 } & \multirow[b]{2}{*}{$\frac{0:}{\underline{E}}$} & \multirow[b]{2}{*}{ 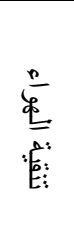 } & \multirow[b]{2}{*}{ 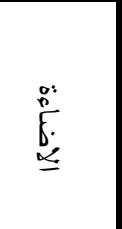 } & \multirow[b]{2}{*}{$\frac{[:}{\stackrel{0}{0}}$} & \multirow[b]{2}{*}{$\frac{C}{E}$} & \multicolumn{3}{|c|}{ المواد المكملة } & \multicolumn{3}{|c|}{ 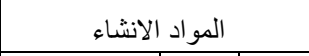 } & \\
\hline & & & & & & & $\begin{array}{l}E: \underline{E} \\
\underline{E} \underline{\underline{E}}\end{array}$ & 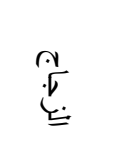 & $\underline{E}$ & $\begin{array}{l}\text { E. } \\
\text { E. } \\
\text { E. } \\
\underline{E}\end{array}$ & 㠿 & $\frac{2:}{q}$ & \\
\hline & $\sqrt{ }$ & & $\sqrt{ }$ & & $\sqrt{ }$ & & & $\sqrt{ }$ & & & $\sqrt{ }$ & $\sqrt{ }$ & \\
\hline \multicolumn{3}{|c|}{ كفاوة البيئة الداخلية } & \multicolumn{2}{|c|}{ المواد والموارد } & \multicolumn{3}{|c|}{ كفاءة الطاقة } & \multicolumn{2}{|c|}{ كفاءة المياه } & \multicolumn{3}{|c|}{ استدامة الموقع } & \multirow[b]{2}{*}{ 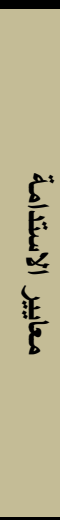 } \\
\hline \multicolumn{3}{|c|}{ التقية الهو ذاتية التنظيف } & \multicolumn{2}{|c|}{ 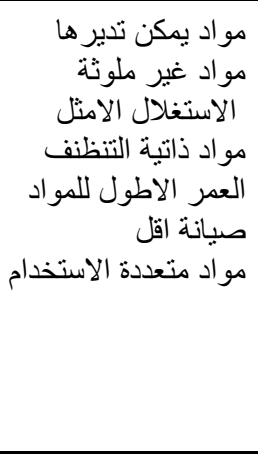 } & \multicolumn{3}{|c|}{ 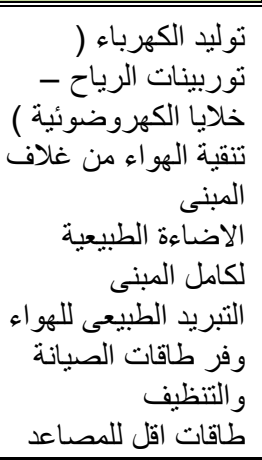 } & \multicolumn{2}{|c|}{ الخزين مياة الامطار } & \multicolumn{3}{|c|}{ 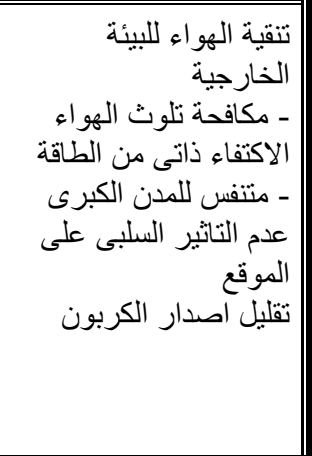 } & \\
\hline \multicolumn{5}{|c|}{ البيئة الداخلية } & \multicolumn{5}{|c|}{ غلاف المبنى } & \multicolumn{3}{|c|}{ الهيكل الانشائى } & \multirow{2}{*}{ 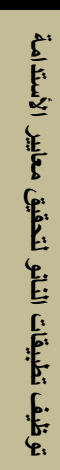 } \\
\hline \multicolumn{5}{|c|}{ 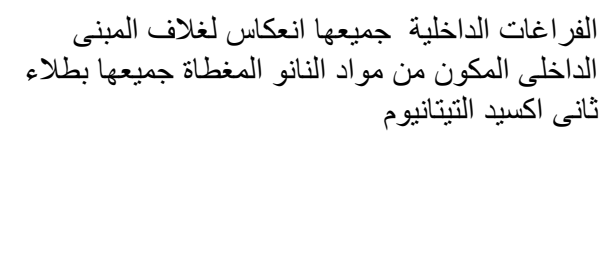 } & \multicolumn{5}{|c|}{ 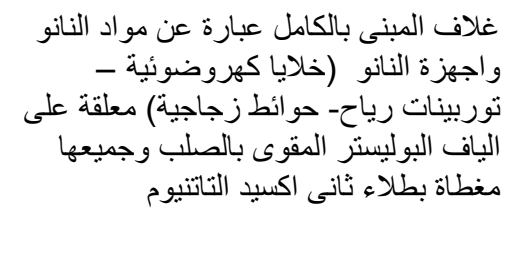 } & \multicolumn{3}{|c|}{ 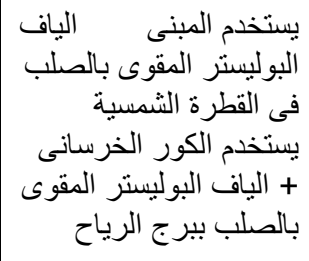 } & \\
\hline \multicolumn{13}{|c|}{ 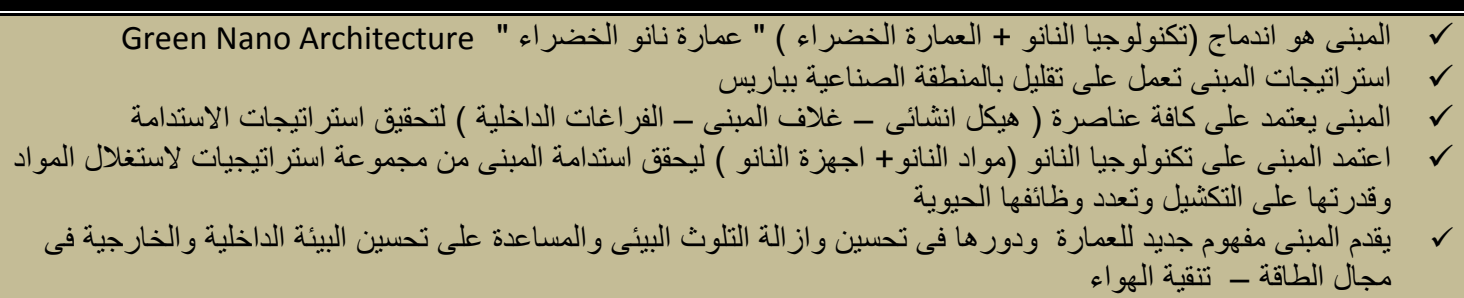 } & $\stackrel{\text { t. }}{\underline{E}}$ \\
\hline
\end{tabular}

\begin{tabular}{|c|c|}
\hline الامتلكه محل & تطبيقات تكنولوجيا النانو \\
\hline
\end{tabular}




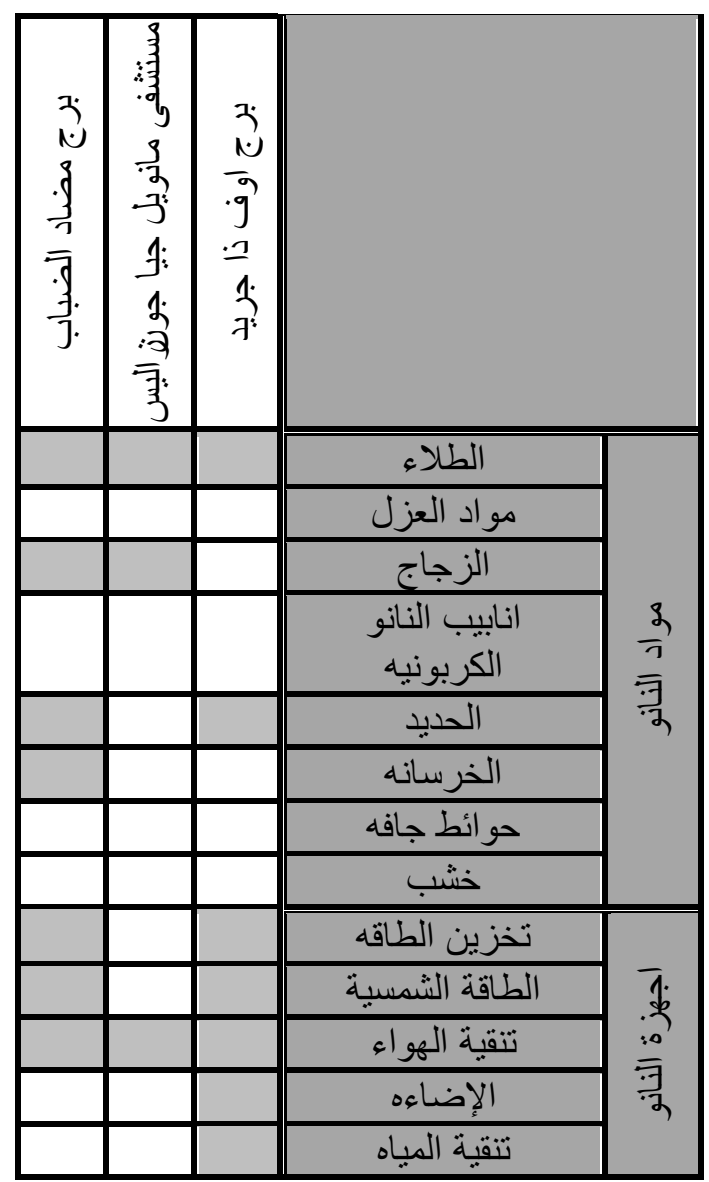

من خلال الدراسة التحليلية ل لأمثلة السابقة و التي قامت بتحقيق

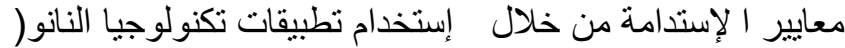

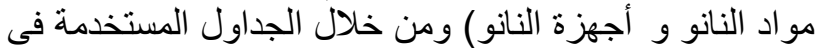

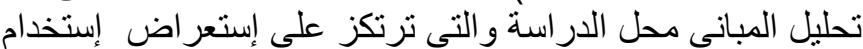

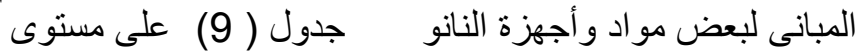

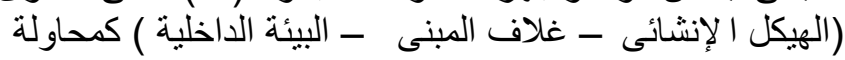

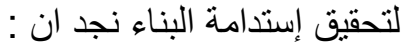
1 - إمكانية الوصول إلي تحقيق إستدامة البناء من خلال

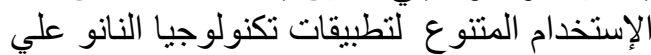
المباني تبعاً لطبيعة كل مبني و الظروف البيئية الدحيطة به. r - من المشاريع الأكثر إستخداماً لتطبيقات تكنولوجيا النانو كان برج مضاد الضبابلذلك كان من أكثر الآمثة تحقيقا

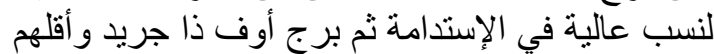

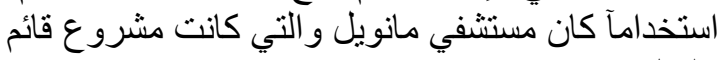

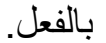

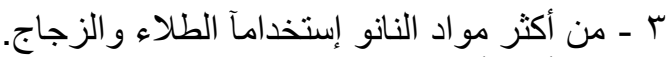
ـ - من أكثر أجهزة النانو إستخدامآ كانت لتنقية النقائ.

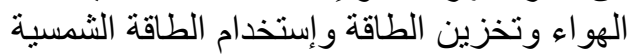
5- نجاح إستخدام تطبيقات النانو مع الآفكار المعمارية الطية

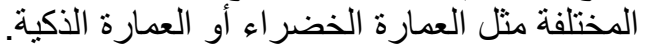

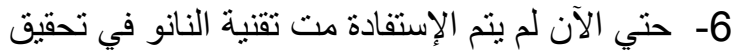

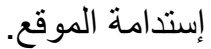

\section{6- 6 النتائسج والتوصيات}

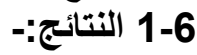

ا ـادي إندماج تكنولوجيا النانو والعمارة الي تغير الفكر المعماري وظهور أنماط جديدة من المباني مثل عمارة النانو

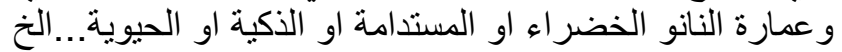

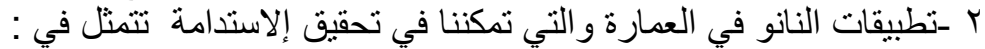

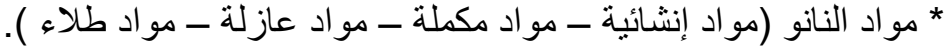

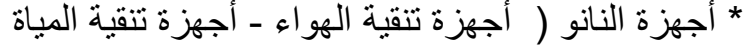
ـ أجهزة الطاقة الثمسية ـ أجهزة تخزين الطاقة ـ الإضـاءات ـ خلايا النانو المتعددة الوظائف ).

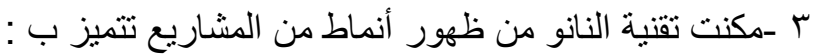

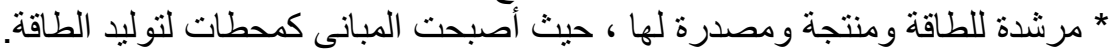

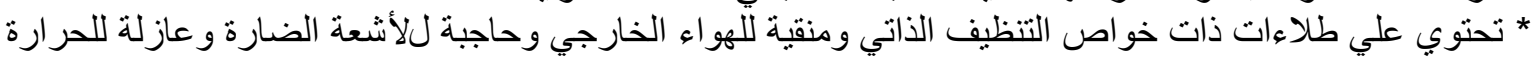

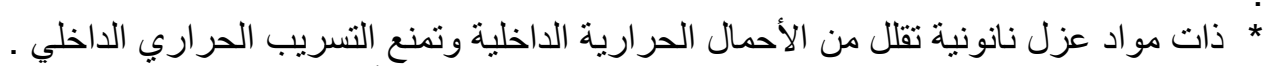

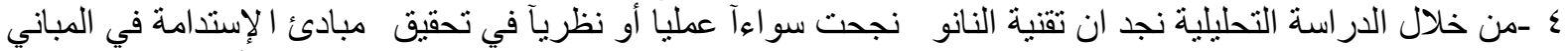

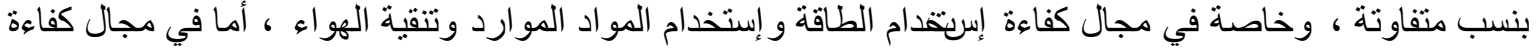

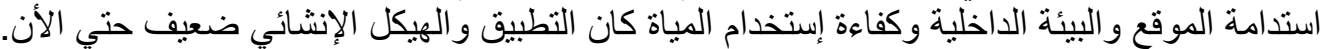
ه - امكانية تطبيق تكنولوجيا النانو علي المباني أثناء عملية التصميم أو علي المباني القائمة لرفع كفائتها. 


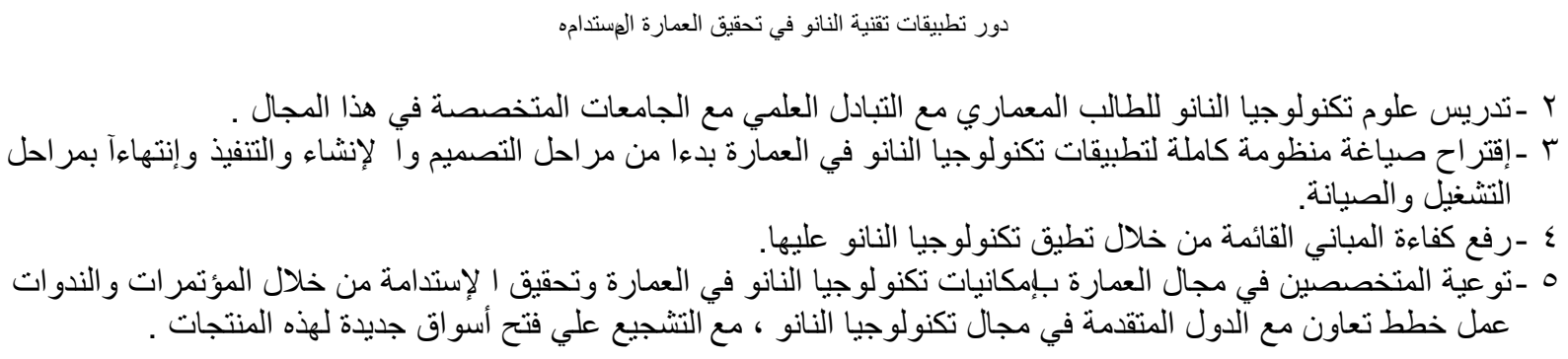

1. Abu Dhabi Urban Planning " Estidama(2010), http://www.estidama.com .

2. Edward Cupoli: Nanotechnology and Economics - The Relationship Between Nanotechnology and Economics, http://www.azonano.com, 2010.

3. Establishment of Egyptian Green Building Council " GPRS" : Egyptian Green Pyramid Rating System "Version 0.1" . http://egyptgbc.org/EGBC Presentation/EGBCfinal.pdf

4. George Elvin, Nanotechnology for Green Building: 2007, greentechforum.net .

5. Green Globes-Building Environmental Assessments, site: http://www.greenglobes.com Comprehensive Assessment System For Building Environmental Efficiency (CASBEE).

6. H.dosch-M.H.Van de voorde: Gennesys White Paper, Max Planck Institute for Metallforschungh Stuttgart, 2009

7. Hessen Nanotech: Application of Nanotechnologies in the Energy sector, Hessian ministry of economy, transport, urban and development, Germany, volume9, 2008.

8. http://ezinearticles.com/?Sustainable-Green-Architecture\&id=715327

9. http://inhabitat.com/anti-smog-architecture-a-catalyst-for-cleaner-air-in-paris

10. http://www.estidama.com .

11. http://www.ibec.or.jp/CASBEE/english/ .

12. http://www.nanowerk.com/spotlight/spotid=2225.php.

13. Leadership in Energy and Environmental Design Green Building Rating System. http://www.usgbc.org/leed .

14. Mexico City Hospital, http://www.medicaldaily.com/mexico-city-hospital-eatspollution-torre.

15. Michel Berger: Nanotechnology's potential to reduce greenhouse gases, 2007,

16. Nanotechnology \& Society: introduction at the university of California, centre of nanotechnology society,2010, http://www.cns.ucsb.edu/about/nanotechnology-society

17. Nanotechnology In Architecture, http://greendimensions.wikidot.com/nanotechnology-in-architecture.

18. Nanotechnology's potential to reduce greenhouse gases. http://www.nanowerk.com/spotlight/spotid=2225.php

19. National Institute of Building Sciences, Whole Building Design guide. http://www.wbdg.org/design/sustainable.php .

20. Off the Grid: Sustainable Habitat2020, http://www.popsci.com/environment/article

21. Problem: Pollution / Solution: Sustainable Habitat 2020, http://www.popsci.com/environment/article/2010-09/life-edge?page $=2 \% 2 \mathrm{C} 3$

22. The Building Research Establishment Environment Assessment Method, site: http://www.breeam.org .

23. William Brister: Sustainable green Architecture .2007,

O ا -نهى علوى الحبشى:"ما هى تقنية النانو" ،مكتبة الملك فهد الوطنية ، جدة ، يوليو 2011. 